\title{
Index for Volume 91
}

AUTHOR AND SUBJECT INDEX. Pages indicating errata are in italic. "S" indicates June abstract supplement. Publication number P-2001-1030-01O.

Abad, J. A., S1

Abad, Z. G., S1

Abbas, H. K., 1141, S1

Abbasi, M., S1

Abbasi, P. A., S1

Abd El-Aziz, F. H., S37

Abdalla, M. E., S181

Abd-Elgawad, M. M. M., S129

Abdul Karim, N., S2

Aboul Eid, H. Z. M., S129

Abril, M., S2

Acacia koa, dieback, in Hawaii, S3

Acer negundo, red stain etiology, S64

Achar, P. N., S185, S187, S191

Acidovorax avenae, on watermelon and cantaloupe seeds, bio-PCR for detection, S74

Adachi, K., S38, S55, S165

Adams, B. J., S173

Adams, G. C., S9, S13, S101, S111

Adams, M. J., S151

Adams, P. D., S2

Adaskaveg, J. E., S29, S58, S62, S84, S184

Adkins, S., 747, S2

Adler, P. H., S102

Aerobiology, air quality, in science building, S111

Afzal, J., S169

Agaricales, Rocky Mountain Alpine Project, S107

Agariceae, tropical and subtropical, literature survey, S120

Agaricus bisporus, dry bubble disease, molecular phylogenetic analysis of pathogen, 905

Ageratum yellow vein virus, on malvaceous hosts, satellite DNAs, Sudan, S41

Agriculture technologies, precision, S166

Agrobacterium spp.

-T-DNA transfer system, macromolecular transfer, S161

-A. tumefaciens: chromosomal gene in tumorigenesis, homolog, S44; Fusarium oxysporum transformation mediated by, mutagenesis and gene transfer, 173; plant oil effect, S37; in soil and surface water, bacteriophage isolation, S25

$-A$. vitis, on grape and tobacco, hypersensitivity, 966

Agrostis stolonifera, brown patch, fungicide strategy, S203

Ahlers, C. A., S197

Ahmed, H. U., S30

Ahn, K.-K., 165

Ahrén, D., S173

Aime, M. C., S101

Aist, J. R., S21, S123, S166, S193

Ajwa, H., S80

Akimitsu, K., S70

Akridge, J. R., S35, S138

Aks, S. E., S110

Albee-Scott, S., S101

Albert, V. A., S105

Albibi, R., S16

Aldwinckle, H. S., S66

Alexander, H. M., S22, S30

Alexander, S. A., S2

Alfalfa mosaic virus, on soybean, chimeric rabies peptide expression, 941

Alfalfa

-brown root rot: identification protocol, S39; occurrence, S184

- cottony snow mold, cutting frequency and resistance, $\mathrm{S} 41$

—powdery mildew, Idaho and Oregon, S64

Alfenas, A. C., S4, S64, S119

Ali, A., S2
Ali, S., S2, S29, S30

Aliquandostipitaceae, dimorphic ascomata, S113

Allen, C., S95

Allen, M. F., S117

Allen, R., S134

Allen, W., S32

Alleyne, A. T., S2

Allodapa suctoria, dormancy, termination, S141

Alminaite, A., S91

Almond

- pathogens, PCR for detection, S102

-Phytophthora spp., canker development and inoculation time, S11

Alnus glutinosa, phytoplasma, in Lithuania, S91

Alpinia malaccenses, endophytes from, $\mathrm{S} 104$

Al-Rehiayani, S. M., S129, S133

Alteri, C., S11

Alternaria spp.: on citrus, molecular systematics, S190; on Poaceae, species differentiation, S109; on tangerine and its hybrids, population structure worldwide, S188

- A. alternata: on citrus, phylogeography, S70; misidentification, S76

Alvarez, A. M., S3, S46

Alvarez, E., S101

Alvarez, J., S3

Amador, J., S199

Amanita spp.

—Hypomyces hyalinus on, S111

Amano, T., 1166

Ambruzs, B., S9, S87

American Phytopathological Society

-annual report, 15

-Extension Award, 25

-fellows, 20

-International Service Award, 28

- Lee Hutchins Award, 26

- Novartis Award, 27

—officers, representatives, and committees, 13

- presidential address, 17

- Ruth Allen Award, 24

- Teaching Award, 29

Ames, K. A., S10, S70

Amoracia rusticana, nematodes parasitic to, Illinois, S144

Anas, O., S139

Anderson, A. J., S9, S48, S49, S51, S63, S98, S104

Anderson, C. E., S134, S141, S145

Anderson, J. A., 572

Anderson, J. B., S106, S107

Anderson, J. L., S123

Anderson, J. M., S173

Anderson, K., 558

Anderson, L. M., S190

Anderson, M. G., S3

Anderson, R. A., S178

Anderson, R. C., S3

Anderson, T., S87, S130, S132, S145

Andrade, G. P., S202

Andrade-Piedra, J. L., 1189

Andrews, D. L., S30, S83, S165

Anguina tritici, on wheat, development, S129

Anisogramma anomala, on eastern filbert, in-

crease in Pacific Northwest orchards, 1214

Annis, S. L., S3, S108, S121

Annulatascaceae, pruning, S105

Ansan-Melayah, D., 70

Anthurium, phylloplane bacteria, bioprotection, S3

Antignus, Y., 565

Antoniw, J. F., S151

Anwar, S. A., S129

Aphanomyces spp.
-A. cochlioides, oospores, viability, S25

-A. euteiches: on alfalfa, races in Midwestern United States, S57; on alfalfa, resistance, S91; DNA markers, PCR-based assay, S191; on pea, biocontrol with bacteria, 383

Aphelenchoides sp., Trichoderma harzianum affected by, biocontrol, 301

Apoga, D., S149

Appel, D. N., S13

Apple stem pitting virus, detection through RNA amplification and probing, 1085

Apple

- blister spot, antagonistic bacteria in British Columbia, S189

-blue mold: harpin-induced resistance, S166; harpin treatment, S193; Metchnikowia pulcherrima as biocontrol agent, 1098

- core rot fungi, control in California, S187

-decay fungi, sucrose/ $\mathrm{CaCl}_{2}$ for, $\mathrm{S} 15$

- disease in Ohio, S15

-fire blight: serratine P effect, exopolysaccharides, $\mathrm{S} 15$; biocontrol, $\mathrm{S} 45$; temperature and biocontrol, S73

- fruit mold, harpin-induced resistance, S21

- gray and blue mold, yeasts for control, S21

-in orchard replant soil, wheat cultivation and seed meal amendment, S59

- postharvest decay, biocontrol, heat treat and MCP treatment, S55

— postharvest diseases, yeast antagonists, molecular tools, S154

- postharvest pathogens, bacterial antagonists, S181

- postharvest rot, yeasts, $\beta$-1,3-glucans and galacturonic acid effect, S23

-replant disease, wheat cultivars for control, S33

-root pathogens, suppression by Brassica napus seed meal, 673

-scab: myclobutanil resistance, 102; Venturia spp. and hypersensitivity, 633

-sooty blotch and flyspeck, disinfectants, S7

-white rot, ultrastructure, latent infection, 165

Arabidopsis, downy mildew, signaling and resistance, S159

Arachis diogoi, $M i$ gene from, detection, S130

Araki, M., S136

Arauz, L. F., S32

Arauz, W., S3

Araya, C. M., S3

Arbutus menziesii, decline, nitrogen and mycorrhizae, $\mathrm{S} 183$

Arceuthobium tsugense, on western hemlock, biocontrol, S183

Arelli, P., S139, S147, S169

Arioan, R. V., S135

Armillaria spp.

—on conifers, Colorado campgrounds, S127

- genecological aspects, molecular tools, S156

- phylogeny in southern hemisphere, S106

—rhizomorphs, oxygen effect, S62

Armstrong, K., S183

Aroian, R. V., S145

Arseniuk, E., S20

Arul, J., S194, S196, S198

Ascomycetes

-filamentous, evolution from multiple-gene analysis, S117

-freshwater: distribution in Hong Kong, S125; Great Smoky Mountains National Park, S121

—in freshwater habitats, biodiversity, S163

—in lakes and bogs, Wisconsin, S110

—in Mexico, new species, S110

Ascomycota 
-freshwater, pantropical, S123

-loculoascomycetes, lineages and gene analysis, S118

Ashburn, D. R., S3

Asparagus, Fusarium crown and root rot, mycorrhizae, formononetin and $\mathrm{NaCl}$ effect, S26

Asparagus densiflorus, root exudate properties, S184

Aspergillus spp.: identification key, S115; mitotic spindles, formation, S162; section Flavi, allozyme analysis, $\mathrm{S} 43$

-A. flavus: aflatoxin production, culture conditions and generations, S112; on corn, embryo protein and resistance, S16; on cotton seed, monitoring strains in desert southwest, S181; on leguminous trees, aflatoxin in Arizona, 913; $\mathrm{S}$ strain, in Texas, $\mathrm{S} 19$

-A. fumigatus, genetic homogeneity, S121

-A. nidulans: cell polarity, genes, S123; septation regulation, $\mathrm{S} 162$; septin $\mathrm{AspB}$ in new growth, S126; swo mutants, mitotic and meiotic maps, $\mathrm{S} 117$

-A. parasiticus, on corn, spread, S89

Assante, G., 457

Asselin, A., S194

Assis Filho, F. M., S4

Assunção, M. S., S139

Atibalentja, N., S129, S130, S139

Attard, A., 70

Attias, M., 408

Aureobasidium pullulans, heat and salt stress, salt march ecosystem, $\mathrm{S} 118$

Author index, S205

Avant, J., S4

Avendaño, F., S130

Averre, C., S12

Avila, F., S201

Avis, T. J., 249, S193

Avocado, anthracnose, postharvest control, 143

Avocado sunblotch viroid, detection with PCR, S183

Ayala, L., 55

Ayeni, G. A., S38

Aylor, D. E., 1189, 1214, S4

Ayres, A. J., S7

Azad, H. R., S14

Aziz, J., S169

Baayen, R. P., 1037

Babadoost, M., S4, S16, S42, S43, S144

Babbitt, S., S71

Bacillus spp.

- B. amyloliquefaciens: on mulberry, antimicrobial activity of culture filtrate, 181

-B. mojavensis: on wheat, seedling blight control, S4

-B. mycoides: biocontrol agent, for Botrytis on strawberry, 621

Bacon, C., S4, S32, S51, S98

Bacteria

- letter to editor, classification and nomenclature, 617

—quorum sensing, quenching infection, S160

-quorum sensing-regulated behavior, signals, S160

Badhamia gracilis, biosystematics, S106

Bae, H. N., S4

Bae, Y.-S., 301, S181

Baek, S. J., S4

Baenziger, P. S., S123

Baider, A., 579, 1074

Bainbridge, B. W., S121

Baird, R. E., S203

Baker, C. J., S4

Baker, F. A., S156

Baker, S. E., S5

Bakker, E., S147

Bakker, J., 753, S21, S143, S147, S174
Bakshi, S., 1062

Balbyshev, N. F., S178

Balconi, C., S5

Baldwin, J. A., S201

Balesdent, M. H., 70

Balint-Kurti, P., S61

Banana (see also Musa acuminata)

- biocontrol of wilt and nematodes, S82

Banana streak virus, detection by IC-PCRELOSA, S22

Banihashemi, Z., S5

Banik, M. T., S102, S118

Banko, T. J., S5

Banks, D., S16

Banttari, E. E., S97

Bao, J. R., S5, 449

Barbercheck, M. E., S139

Barberry, rust host, survey in Minnesota, S71

Barbetti, M., S48

Barbosa, J. G., S64, S119

Bardinelli, T. R., S5

Bar-Eyal, M., 687

Bargabus, R. L., S5

Barker, A. D., S167

Barker, R., S20

Barker, S. A., S103

Barley, Rhizoctonia root rot, spatial distribution, S70

Barley yellow dwarf virus

- RMV isolates and clones, transmission efficiency of vector, 792

-on wheat: integrated management, S81; resistance from Thinopyrum intermedium, 55; weather effect, S10

Barnes, C. W., S6

Barnes, I., S77

Barnes, J. S., S5, S202

Barnett, C. J., S102

Baroni, T. J., S102

Barreto, D., S71

Barrett, B., S139

Barthe, G. A., S47

Bartnicki-Garcia, S., S122

Barton, M. M., S114

Bartz, J. A., S6

Barve, M. P., S6

Basaran, P., 966

Basart, J. P., S167

Basim, E., S6

Basim, H., S6, S90

Bassett, C. L., S7

Bassi, B., S18

Bates, G. D., S65, S201

Bates, S. A., S7

Batrachochytrium spp., on amphibians, PCR assay, S108

-B. dendrobatidis; on amphibians, physiology, S121

Batten, J. S., S7

Batzer, J. C., S7

Bauer, S. J., S139

Bauer, W. D., S160

Baum, T. J., S134, S161

Baune, M., S35

Bauske, E. M., S82

Bautista, J., S142

Bayman, P., S116

Bean dwarf mosaic virus, virus-host interaction, GFP tagging, S44

Bean pod mottle virus

-Mexican bean beetle relation, mutualism, S65

-resistance, transgenic lines, capsid polyprotein, 831

- Soybean mosaic virus combination, seed coat mottling, S39

-on soybean: seed and leaf beetle as inoculum source, S20; seed effect, S100

Bean, T. G., S175
Beard, C. E., S102

Beattie, G. A., S78

Beaubien, Y., S156

Beaver, J. B., S199

Beck von Bodman, S., S196

Beck, C., S67

Beck, J. J., S102

Becker, E. M., S181

Becker, J. O., S7, S134, S174

Beckhove, U., 127

Beckman, T. G., S140

Becton, C. B., S78

Bedford, K. E., S81, S181, S189

Beede, R. H., S24

Beer, S. V., S21, S166, S193

Beet curly top virus, encoded proteins, intracellular distribution, $\mathrm{S} 83$

Beet necrotic yellow vein virus

- Beet soilborne mosaic virus comparison, field distribution patterns, S96

-remote detection, S84

Behe, C., S7

Behm, A. L., S7

Bejarano-Mendoza, C. A., S199

Bekal, S., S130

Belair, G., S130

Belal, M., S133

Bélanger, R. R., 249, S193, S194, S196

Belasquez, J., S7

Bell, D., S135

Bell, F. W., S62

Belling, R. A., S102

Belzile, F., S194

Bemisia tabaci

-Tomato yellow leaf curl virus vector: resistance and transmission, 1209; transmission pathway, 188

Bender, C. L., S204

Bendezu, I. F., S130

Benhamou, N., 730, 782, S168

Ben-Joseph, R., 1209

Benson, D. M., S41

Bentgrass, Pythium aphanidermatum, biocontrol, S46

Berbee, M. L., S111, S113, S122, S164

Berg, M., S8

Bergemann, S. E., S102

Berger, R. D., 212

Bergman, C. I., S175

Bergstrom, G. C., 642

Bernard, E. C., S130, S131

Bernard, R. L., S39

Bernardy, M., S29

Berney, M. F., S131

Bernhard, F., S160, S196

Bernick, S., S8, S72

Bernier, J., S193

Bernier, L., 369, S8, S56, S194

Berretta, M. J. G., S47

Berto, P., 1030, S8

Bertrand, P. F., S85

Berube, J. A., S124

Best, V. M., S61

Bextine, B., S8, S11

Beyer, D. M., S3, S8, S195

Bhat, R. G., S8, S45, S114

Bhatia, A., S70, S88

Bick, J. A., S8

Bidartondo, M. I., S163

Bienapfl, J. C., S9

Bies, S., S63

Bigelow, D. M., S181

Bijman, V. P., S64, S187

Biles, C. L., S99

Binder, M., S102, S164

Biological control

-Aphelenchoides sp. for Trichoderma harzianum, biocontrol efficacy, 301 
-Burkholderia cepacia for pea oomycete pathogens, 383

-Cladosporium tenuissimum for Cronartium flaccidum and Peridermium pini, 457

-Colletotrichum mutants for anthracnose on avocado, 143

- Coniothyrium minitans for Sclerotinia sclerotiorum on lettuce, 221

- discovery in substrate competition of soil microorganisms, $\mathrm{S} 98$

-fire blight suppression, compatible biocontrol agents, S190

-Fusarium oxysporum on tomato roots, wilt control, 449

-Fusarium proliferatum for Plasmopara viticola, on grape, 1062

-Hirsutella rhossiliensis or nematode, soil $\mathrm{pH}$, 324

-Metchnikowia pulcherrima for apple blue mold, 1098

-Microsphaeropsis sp. for Rhizoctonia solani on potato, 782

-nematode antagonistic compounds from fungi, S139

-Phytophthora cinnamomi with eucalyptus mulches, 847

—Pichia guilermondii and Bacillus mycoides, combining agents, 621

- potting mix effect on damping-off of radish and root rot of poinsettia, Rhizoctonia solani, 1116

- Pseudomonas fluorescens in rhizosphere, biotic factors, 873

- Pseudomonas syringae and Pantoea agglomerans, leaf colonization pattern, S78

-Pseudozyma flocculosa for powdery mildew, molecular analysis, 249

-Rhizobium etli for Meloidogyne incognita, endophytic colonization, 415

- Serratia marcescens for Colletotrichum orbiculare in cucumber, 593

-Stenotrophomonas maltophilia: chitinases, 204; type III secretory pathway, S75

- technology transfer project, in Germany, S108

-Trichoderma harzianum: to Botrytis cinerea 1172; for Meloidogyne javanica, 687

- tritrophic interactions, S181

-Ulocladium atrum for Botrytis cinerea: on strawberry, 1030; water potential effect, 485

Biopesticide, Messenger, bioassay development, S74

Bioremediation, biotechnology relation, transgenic plants and environmental cleanup, S157

Biotechnology

-disease resistance, benefits to growers, $\mathrm{S} 82$

-food allergens, labeling, and communications, letter to editor, 524

Bipolaris sorokiniana

—extracellular matrix, S149

- on tall fescue, resistance induced by Stenotrophomonas maltophilia, S48

-on turfgrass, biocontrol with Stenotrophomonas maltophilia, 204

- on wheat, in Washington, S189

Bird, C. E., S103

Bird, D., S142, S159

Bird, G. W., S131

Bird, J., S42

Bischoff, J. F., S103

Bishop-Hurley, S., S53

Blachere, F. M., S182

Black, M. C., S54

Blackwell, M., S103, S124, S127

Blanchette, R. A., S64

Blankenheim, Z., S9

Blaxter, M. L., S134

Blee, K. A., S9, S98

Bleyer, G., S12, S78
Blodgett, A. B., S9

Blodgett, J. T., S9

Blok, V. C., S10

Blom, T., S32

Blomquist, C. L., S152

Bloodworth, B. K., S201

Bloomer, P., S106

Blueberry

-Monilinia vaccinii-corymbosi, biological interactions during infection, S65

-mummy berry disease: pseudosclerotial germination, 77; sequential sampling, 348

- postharvest fungal decay, ozonated air effect, S201

- Septoria leaf spot, fungicides for, S10

- stem and leaf diseases, survey, S3

Blueberry red ringspot virus, genomic organization and sequence analysis, S195

Blumeria graminis, surface sensing and geometric modeling, S149

Blunt, T. D., S9

Boa, E. R., S32

Boehm, E. W. A., 428, 665, S9, S57, S103

Boehm, M. J., S48, S80

Boekhout, T., 249

Boellmann, J., S104

Boerboom, C. M., S176

Boerjan, W., 1069

Bokonon-Ganta, A. H., S168

Boletales, brown rot saprophytes and ectomycorrhizal symbionts, S102

Bolger, P. M., S170

Bolker, M., S165

Bolland, M., S85

Bond, E. O., S10

Bond, J. P., S10, S92, S131, S144

Bond, W. P., S10

Bonello, P., S9

Bongers, T., S134

Bonsall, R. F., 35

Boosalis, M. G., S175

Boozer, R., S82

Borneman, J., S90, S98

Borst, J. W., S143

Bosques, A., S199

Botryosphaeria spp.: on Leyland cypress, in Tennessee, S3; RAPD characterization, Diplodia anamorphs, S83

-B. dothidea: on apple, ultrastructure, 165; on pistachio, population on other hosts, 665 ; on pistachio, population structure in hosts in California, S57; on Protea magnifica, endophyte, S23

Botrytis spp.

-B. aclada: B. byssoidea distinct from, differentiation method, 527; on onion, subgroup analysis, S120

- B. allii, on onion, latent infection, detection, S17

- B. cinerea: acidic electrolyzed oxidizing water effect, S12; on apple, fungicide resistance and vegetative compatibility, S81; benzimidazole and dicarboximide fungicide resistance, 307 ; biocontrol agent, S18; biocontrol with Trichoderma harzianum, nutrient-activated conidia, 1172; on kiwi, natural resistance mechanisms, S96; in phylloplane, competition for nutrients, S12; on rose debris, biocontrol with Clonostachys rosea, S119; on rose, sporulation reduced by Clonostachys rosea, S64; on strawberry, biocontrol with yeast and bacteria, 621; on strawberry, fungicide resistance, S204; Ulocladium atrum antagonistic to, water potential, 485; Ulocladium atrum control by, on strawberry, 1030

Boudon-Padieu, E., 741

Boudreaux, J. E., S204

Bourett, T. M., S162
Bouthillier, M., S29

Bouton, J. H., S144

Boutsika, K., S10

Bowden, R. L., S91

Bowen, K. L., S10, S13

Bowers, J. H., S10

Boyd, M. L., 913

Boyd, S. H., S90, S198

Boydston, C. M., 440

Bradford, J. M., S142

Bradley, C. A., S10, S70, S175

Bradshaw, H. D., Jr., 981

Brady, J., S11

Braga, G. U. L., S104

Braga, G. W., S63

Braim, M. A., S7

Brand, J., S10, S86

Brandwagt, B. F., S161

Brannen, P. M., S10

Brantley, E. A., S111

Brantner, J. R., S95, S175

Brassica spp., downy mildew, mycorrhizal effect, S187

-B. napus: Leptosphaeria maculans, genetic control and host range, 70; seed meal amendment role, apple root, pathogens, 673

-B. rapa, black rot, seed transmission, $\mathrm{S} 14$

Braun, U., S107

Breaden, L., S37

Brecht, M. O., S11

Bredehoeft, M., S48

Breeuwsma, S., 1037

Brem, D., S104

Bremia lactucae, on lettuce, spatial analysis and geostatistics, 134

Brenneman, T. B., S11, S201, S202, S203

Breuil, C., S8, S49, S56, S93, S185, S186, S191

Brewer, K. K., S170

Brewster, V. A., S11

Bridges, A. C., S142

Briggs, K. B., S191

Bristow, P. R., S182

Brito, J. A., S173

Britton, K. O., S54

Broeckelman, B. M., S22

Brome mosaic virus, in barley guttation fluid, cell death response, 440

Bromus erectus, pathogenic endophyte, host shift, S104

Bronson, C. R., S87, S95, S180

Brooks, D., S159

Brooks, M. D., S39

Brown, A. F., 293

Brown, D. J. F., S10, S15, S39, S46, S65

Brown, J. (Canada), S182

Brown, J. K. (AZ), S11, S41, S42

Brown, R. L., S16

Brown, W., S9, S23, S32, S87

Browne, G. T., S11, S12, S91

Bruening, G., S11

Bruhn, J. N., S62, S104, S156

Brule-Babel, A. L., S60

Brumbley, S. M., S158

Bruns, T. D., S125, S163

Brunsfeld, S. J., S156

Bruton, B., S8, S11, S99

Bryan, A. D., S12

Büche, C., S12

Bucher, E. S., S12

Buck, J. W., S12

Budge, S. P., 221

Bujold, I., S21

Bull, C. T., 617, S17

Bulluck, L. R., III, S12

Bultman, T. L., S117

Bunkers, G. J., S13

Burch, K., S10

Burchett, S. L., S60 
Burdon, J., S127

Burdsall, H., Jr., S20, S102

Burgess, L. W., S13

Burgess, T., S22

Burkhead, J. L., S157

Burkholderia spp.: on rice seed, pathogenicity, 282; in soil, management practice effect, $\mathrm{S} 18$

-B. cepacia: biocontrol of Rhizoctonia stem rot of poinsettia, pyrrolnitrin role, S41; complex in soil, urban environment, S63; pathogens to humans, S173; on pea, postinfection biocontrol of oomycetes, 383; strains, pathogen relation, S173

Burns, D. J., S30

Burow, M., S17, S130

Burpee, L. L., S63, S89, S148, S203

Burr, A. T., 966

Burr, T. J., 966

Burr, W. F., S89

Bursaphelenchus xylophilus, on Scots pine, in New York, S196

Buss, S., S131

Bussaban, B., S104

Butrón, A., S34

Buttke, C., S175

Buttonow, L. M., S176

Buyck, B., S119

Buzayan, J. M., S11

Cacao

-black pod, leaf disk assay, S10

-witches' broom, parasite sporulation, S79

Cacka, J., S82

Caesar, A. J., S61

Cafaro, M. J., S104

Cahagnier, B., S36

Caldwell, R. W., S9, S61

Calibrachoa sp., spherical virus from, first report, S55

Calkin, J., S82

Calvert, L. A., S13, S168

Camacho, F. J., S125

Camara, M. P. S., S104

Camilli, K. S., S13

Campbell, H. L., S13

Campbell, J. (IL), S105

Campbell, J. F. (KS), S173

Campbell, K. W., S17, S36

Campbell, R. J., S176

Campydora spp., status, S139

Canaday, C. H., S3, S81

Candida albicans, drug resistance, population genomics, $\mathrm{S} 107$

Candresse, T., 84

Canola (see also Rape)

-blackleg, fungicide and sowing time, Australia, S48

-Fusarium wilt, in Canada, S185

Cantaloupe (see also Melon)

—powdery mildew, chemical management, S59

Cantherellus spp., habitats in Oregon mountains, S106

-C. formosus, genetic structure, microsatellite loci, S109

Capsicum spp. (see also Pepper)

- viruses, resistance to, S75

Carballo, O., S79

Carbone, I., S115

Cardenas, C., S3

Cardin, L., 84

Cardwell, K. F., S38, S171

Carisse, O., 782, S21, S72, S89, S193, S197

Carle, S. A., 966

Carmargo, L. E. A., S158

Caron, S. J., 249, S193

Carranza, J., S163

Carras, M. M., S89

Carrington, J. C., S161
Carriquiry, A. L., S62

Carris, L. M., 935, S105, S151, S182

Carroll, J. E., S193

Carroll, R. B., S21, S24

Carrot

-aster yellows, epidemiology in Texas, S54

—cavity spot, mefanoxam application, S27

— leaf blight, control strategies, S195

—winter storage, benomyl spray, S178

Carson, M. L., S11

Carta, L. K., S131, S145

Carter, E., S25, S93

Carter, S. A., S162

Cartwright, R. D., S1, S23, S70

Caruso, F. L., S14, S193

Carver, T. L. W., S149

Casela, C. R., S169

Casper, H. H., S84

Castell, C., S13

Castellano, M. A., S112

Castilla, N. P., S79

Castillion, A., S161

Castlebury, L. A., 935, S105, S151, S164

Castro, A. C., S92

Casuarina equisetifolia, fungi in forests of, Hawaii, S111

Catal, M., S13

Catharanthus roseus

-Phytophthora blight: drip irrigation, S40; phosphite effect, S5

Catlin, N. J., S14, S193

Cauliflower mosaic virus

- hypersensitivity, uncoupling sequences, S69

-in transgenic Arabidopsis, lethal mutation, S98

Cavaletto, J. R., S1, S88

Cawly, J., S14

Ceccardi, T. L., S47

Cenococcum spp., sclerotia, ectomycorrhizae, in forests, S103

Center, T. D., S75

Cephalosporium gramineum

- on wheat, toxin effect, 702

-on winter wheat: cover photo, March; transformed isolate, 232

Ceratobasidium sp., on Douglas fir, web-blight similarity, S189

Ceratocystis spp., on softwood logs, deep stain, Canada, S56

-C. albofundus, on Acacia mearnsii, in Africa, S77

-C. fagacearum, on oak, trench insects, S95

-C. fimbriata, host specialization, $\mathrm{S} 4$

Cercospora sp., on corn, phylogenetic analysis, 648

- C. beticola, genetic diversity, fungicide tolerance, $\mathrm{S} 94$

-C. zeae-maydis: C. sorghi comparison, $\mathrm{S} 11$; Cercosporin biosynthesis gene, S81; on corn, fungicides for, 477; phenotypic variability, S24; precocious sporulation, S52

Ceresini, P. C., S105

Ceri, H., S58

Cerkauskas, R. F., S14, S182

Cervantes, L. A., S83, S190

Cervera, M. T., 159

Cha, J.-S., S53

Chacón, G., 993

Chaetomium globosum, in barley roots, hypodermal suberization and structural barriers, S75

Chagas, M. C. M., S7

Chakraborty, S., S14, S50

Chaky, J., 558

Chalara elegans, on bean, virulence assessment, S73

Chambers, J. G., S105, S116, S121

Champaco, E. R., S33

Chandler, C. K., S54

Chang, C. J., S14, S54
Chang, H.-S., S159

Chang, K. F., S14, S41

Chanterelle, new species in Pacific Northwest, S109

Chao, C.-H., 361, 856

Chaouch, R., S15

Chardonnet, C. O., S15

Charles, M. T., S194

Charlton, N. D., S92

Charudattan, R., S71, S97

Chase, T. E., S15

Chastagner, G. A., S13, S18, S182

Chatfield, J. A., S15, S169

Chaunopycnis spp., endoglucanase from, characterization, $\mathrm{S} 117$

Chaverri, P., S105

Cheggour, A., S15

Chelle, M., S78

Chellemi, D., S5

Chen, B., S150

Chen, C., S164

Chen, C.-C., 361, 856, S17

Chen, F. J., S15

Chen, J., S16

Chen, P. C., S131

Chen, Q., S15, S39

Chen, R. S., S16

Chen, S. F., S125

Chen, S. Y., S15, S118, S130, S137, S138

Chen, W. Q., S16

Chen, W., S16, S159, S176, S179

Chen, X. (Pa.), 173

Chen, X. M. (Wash.), S16, S97, S182

Chen, Y.-C., S176

Chen, Y.-Q., S106

Chen, Z. B., S176

Chen, Z.-Y., S16

Cheng, D. W., S183

Cheng, M., S31, S184

Cheng, N.-H., S162

Cheng, W., S74

Cheng, Y. L., S194

Chenopodium quinoa

—virus host, universal, S52

-Xylella fastidiosa infiltration of leaves, S11

Cherry

- brown rot in fruit, fungicides and atmosphere packaging, S190

-little cherry disease, closterovirus characterization, 268

- sweet and sour, closterovirus association, detection, 261

Chet, I., 687

Chilvers, M. I., S17

Chinnasri, B., S132

Chitin

— amendment, nematodes and fungi suppressed by, $\mathrm{S} 168$

—nutrient cycling role, S167

Chitosan, disease suppression, S168

Chitwood, D. J., S139, S140

Chlamydomonas reinhardtii, heavy metal-bind-

ing capacity and tolerance, foreign genes, S157

Cho, B. H., S42, S80

Cho, S. I., S49

Choi, H. T., S115

Choi, I.-R., S29

Choi, S. G., S4

Choi, W., S87

Chondrostereum purpureum, biocontrol agent for weeds, forest, S181

Chong, C. S., S167

Chong, S. K., S92

Christie, P. J., S161

Chrobak, M., S90

Chromolaena odorata, pathogens of, South Africa, S22

Chu, F.-H., 361, 856 
Chung, G. C., S42

Chung, M.-H., 361

Church, G. T., S17

Churchill, P. F., S105

Chytrid, systematics, phylogenetic genes, S105

Cicer arietinum

-Fusarium wilt, rhizosphere bacteria and factors, 807

-root exudate, phosphorus acquisition, S85

Cintas, N. A., S17

Cirsium arvense, powdery mildew, first report in North America, S14

Citrus (see also Lemon)

-Alternaria brown spot, model for timing fungicide applications, S88

-blight, gene introduction by Agrobacterium tumefaciens, $\mathrm{S} 47$

- canker: epidemic in Florida, eradication policy, letter to editor, 30; sentinel tree grid system, cover photo, January

- pathogen resistance, genetic transformation, S97

-Phytophthora root rot, commercial soil surfactant, S62

-Phytophthora, root weevil association, S203

- postblossom fruit drop, benomyl effect, S71

- Xylella fastidiosa, genetic diversity in Brazil, 599

Citrus tristeza virus

-aphid transmission, genetic bottleneck, S81

- genomic RNA, capside protein localization, S67

-on sweet orange, in south Florida, S72

Citrus unshiu, disease survey, in Alabama, S60

Citrus yellow mosaic virus, host range and PCR detection, $\mathrm{S} 40$

Civerolo, E. L., S11

Cladonia perforata, photobionts, phylogeographic pattern in Florida, S127

Cladosporium spp.

-C. fulvum, on tomato, secreted protein, S161

-C. tenuissimum: antagonism to Cronartium and Peridermium spp., 457; hyperparasitism on pine rust aeciospores, cover photo, May

Clair, D., 741

Clark, C. A., S56

Clark, J., S106

Clark, T. A., S104, S106

Clarke, B. B., S148, S197, S198

Clarke, J. D., S159

Claroz, J. L., S101

Clavibacter spp.

-C. michiganensis: on alfalfa, host range, S79; hypovirulence, PCR and ELISA assays, S46; on potato, detection with molecular beacon technology, S63

-C. $x y l i$, on sugarcane, genomics, $\mathrm{S} 158$

Claviceps africana, genetic diversity, Australia, S50

Clavulina, Craterellus comparison, sympatric neotropical species, variability, S125

Clayton, K., S74

Clayton, M. K., S61

Clayton-Greene, K., S37

Clements, M. J., S17, S59

Clethra barbinervis, arbuscular mycorrhizae, S118

Cleveland, T. E., S16

Clifford, J. M., S17

Clifton, S., S159

Cline, E., S183

Cline, W. O., S201

Clitopilus spp., phylogenetic profile, DNA sequences, $\mathrm{S} 102$

Cloud, G. L., S18

Clough, G. H., S35

Clum, N. C., S118

Coca, M., 956

Cochliobolus spp., cytological karyotyping, germ tube burst method, 354

-C. carbonum, HC-toxin, effect on duckweed, 1141

-C. heterostrophus: on corn, genomics and pathogenicity, S165; mating type genes, analysis, S122; Tox1 locus complex, S5; virulence factor, common with Fusarium, S56

-C. sativus: on barley, virulence and molecular diversity, 469; on barley and wheat residue, burning effect, S23; on wheat and barley, necrotrophy and toxins, 127

Coconut, Tinangaja viroid, techniques for study, S200

Cody, B. R., S19

Coelho, R. R., 1045

Coetzee, M. P. A., S106

Coffee

-necrotic leaf spot, Rhizoctonia solani anastomosis group 1,1054

—nematodes, survey in Hawaii, S142

-Xylella fastidiosa, genetic diversity in Brazil, 599

Cognet, S., S154

Cohen, S., 1209

Cohen, Y., 579, 1074

Cole, A., S14

Coleoptera, yeasts from gut of, taxonomy, S124

Colgan, W., III, S112

Colgrove, A. L., S132

Colletotrichum spp.: on fruit, population dynamics in southeastern United States, S16; pH increase induced by ammonia, S73

-C. acutatum: on almond, detection methods, S184; on apple, postharvest calcium treatment, S69; culture medium effect on germination and sporulation, S7; genetic diversity, 586; genetic diversity in subgroups, sequence analysis, S55; mating compatibility, subgroups, S33; on strawberry, C. fragariae relation, $\mathrm{S} 2$; on strawberry, germination and sporulation, 659; on strawberry, persistence on other hosts, 986

-C. gloeosporioides: on avocado, postharvest disease, biocontrol, 143; C. acutatum comparison, pectic enzymes, S99; on lupines, in Connecticut, S194; on Stylosanthes spp., new strains, S14

-C. graminicola: Bipolaris maydis interaction, specific genes, S149; on sorghum, genetic diversity, S93; spore germination, hydrophobicity and surface rigidity, 558

-C. lindemuthianum, on bean: molecular diversity, S3; photosynthetic competence, 212

-C. sublineolum, on sorghum: crop mixture effect, 720; infection ultrastructure, 149; tissue colonization, cover photo, February

Collins, A. (W. Va.), S50

Collins, A. A. (N.C.), S18

Collins, G. B., 831

Collins, K. P., S106

Collopy, P. D., 905, S18

Collybia sensu lato, biological species in Costa Rica, S118

Colville, M., S13

Colyer, P. D., S18

Compost, Pythium suppressive soil, disease control mechanism, S60

Concelmo, D., S6

Conifer

- diseases and histopathology, Koch's postulates, S204

- endophytes, detection by PCR and dot-blot assay, S13

-landscape genetic architecture, molecular tools, S156

Coniophora spp., on lemon tree, in Arizona and California, S29

Coniothyrium minitans, biocontrol agent for Sclerotinia sclerotiorum on lettuce, fungicide comparison, 221

Conway, J., 492

Conway, W. S., S15, S55, S69, S73

Cook, C. G., S90, S142

Cook, D. W. M., S18

Cook, R. J., S70

Cooksey, D. A., S76

Cooley, M., S45, S159

Coomans, A., S144

Copes, W. E., 348, S18

Cordyceps spp.: evolutionary origin, sequence analysis, S106; monophyly, Polycephalomyces, S103; multigene phylogeny, Clavicipitaceae, $\mathrm{S} 125$

-C. sinensis: anamorph, transcribed spacers, S106; HeLa cell proliferation effect, S116

Corn (see also Maize)

-aflatoxin and Aspergillus flavus, management in West Africa, S38

—aflatoxin, inoculation techniques in field, S96

-aflatoxin resistance, norsolorinic acid use, S7

-Aspergillus ear rot, aflatoxin, in hybrids, S59

- charcoal rot, marker differentiation, 120

- dent and sweet, ear rot and fumonisin, S115

- ear rot and fumonisin, insect damage effect, S17

-fumonisin in grain, S36

-fungal pathogens on root, in Illinois, S12

- gray leaf spot: fungicides for, 477; phylogenetic analysis, 648; prediction, neural network modeling, S70; temporal and spatial spread, in Iowa, S179

-lesion nematode and water stress interaction, $\mathrm{S} 132$

-non-Rhizoctonia host, irrigation, S23

-red root rot, re-emergence in Colorado, S9

- seedling diseases, seed treatment and no-till, S70

- stalk rot, nitrogen rate and kernel sink sufficiency, S41

-Stewart's disease: flea beetle vector role, S166; risk factors, S177

-Stewart's wilt, CPS virulence determinant, quorum sensing, S196

- sweet: fumonisin production, S50; smut control, S35; Stewart's wilt, leaf blight, rust, trait loci, 293

- virus-associated disease, new in Minnesota, S56

Cornus florida (see also Dogwood)

- anthracnose and powdery mildew, distribution in Michigan, S9

-powdery mildew, resistance, S64

Correa-Victoria, F. J., 63

Correll, J. C., S18, S33, S44, S55, S148

Cortez, A. A., S96

Corylus avellana, filbert blight, spatial and temporal increase in Pacific Northwest, 1214

Costa, L. C., 1045

Costilla, M., S71

Cotton

- charcoal rot: marker differentiation, 120; resistance and breeding lines, S90

- geminiviruses, whitefly transmission, serology in Pakistan, S35

- harpin protein and reniform nematode effect, S68

-nematodes: distribution using electrical conductivity, S139; remote sensing and sampling, S146

-reniform nematode: field response of varieties, S138; Telone II for management, S140

-Rhizoctonia solani and Alternaria macrospora, resistance induced, nonpathogenic species, S195

- seedling disease complex, fungi in Alabama, S69

—wilt, multigene genealogies, races, 1231 
Cottrell, N., S132

Cotty, P. J., 913, S19, S43, S181

Cottyn, B., 282

Cotxarrera, L., S19

Couch, B., S107

Cousins, J. R., S107

Coutinho, T. A., S41, S124

Cover photo

-Cephalosporium gramineum, on winter wheat, transformation, March

— citrus canker in Florida, tree grid system, January

-Cladosporium tenuissimum, hyperparasitism on pine rust aeciospores, May

-Colletotrichum sublineolum, on sorghum, tissue colonization, February

- Cucumber fruit mottle mosaic virus, in cucurbits, June

-Fusarium, on pea root, nonpathogenic isolate, August

- Grape, powdery mildew, October

-Jack pine resistant to Scleroderris canker, December

-mycoparasitism, of Fusarium proliferatum, on Plasmopara viticola, November

-Phytophthora cinnamomi, mycelium, cellulase effect, September

- Rhizobium etli, on Arabidopsis roots, nematode-infected, April

-Venturia pirina, on apple, asci and conidia, July

Covert, S. F., S203

Cowan, M., S19

Cowen, L. E., S107

Cowger, C., S19

Cowpea aphidborne mosaic virus, on peanut, in Brazil, detection, S202

Cowpea chlorotic mottle virus, RNA polymerase from protoplasts, 747

Cradock, K. R., S19

Craigon, J., 708

Cram, M. M., S29

Cranberry

-fruit rot: calcium salt effect, S9; Wisconsin, S61

—storage rot, regression, S67

—upright dieback: cause, S14; in Massachusetts, S193

Crataegus aestivalis, $C$. opaca comparison, leaf blight and fruit mummification, S80

Cripps, C. L., S107, S120

Crisosto, C. H., S69

Crombie, D., S189

Cronartium spp.

-C. flaccidum, Cladosporium tenuissimum antagonistic to, 457

-C. quercuum, growth, carbon source, S109

-C. ribicola, on white pine, imminent decline, montane biodiversity, S155

Crop loss, disease and assessment, scale issues, S157

Crop management, remote sensing, GIS integration, $\mathrm{S} 167$

Crosby, D. G., S187

Crosby, K. M., S19

Crosslin, J. M., S87

Croton yellow vein mosaic virus, characterization, S57

Crous, P. W., S23, S41, S107, S108, S116

Crow, W. T., S132

Crowe, F., S183

Crucifer, bacterial leaf spot diseases, inoculum source, Oklahoma, S204

Cruz, C. D., S64

Cruz, M., S13

Cryphonectria spp.

-C. cubensis: on Eucalyptus spp., hypovirus relation, 628; three new species, S125
-C. parasitica: on chestnut, transposons, S196; on chestnut, vesicle subsets, S90; hydrophobin cryparin role in biology, S47; hypovirus on $C$. cubensis, in South Africa, 628; protein secretion, mycovirus effect, S60

Cubero, J., S19

Cubeta, M. A., S19, S105

Cucumber

—foliar diseases, North Carolina, S26

-leaf spot, greenhouse cultivation in Korea, S51

- powdery and downy mildews, strobilurin resistance, characterization, 1166

- powdery mildew: chalcone synthase and isomerase induction, S194; copper octanoate and copper hydroxide, S189

- systemic acquired resistance, acidic chitinase type III, S91

— systemic resistance, rhizobacteria-mediated, iron role, 593

—wilt and beetles on, cultivar variation, S196

Cucumber fruit mottle mosaic virus, on cultivated cucurbits, cover photo, June

Cucumber green mottle mosaic virus

- molecular characterization, 565

Cucumber mosaic virus

- on bell pepper, age relation, S30

- capsid protein, second-site revertants, S29

- cryopreservation, S38

-RNA silencing suppression, analysis, S162

- vector, subgenomic motor driven, S99

Cucumber necrosis virus, Olpidium bornovanus interaction, molecular studies, S150

Cucumis sativus, phytoalexins, methodology for characterization, S196

Cucurbit

- aphid-borne viruses, survey in South Africa, S19

- bacterial wilt and cucumber beetles, cultivar variation, S60

-fungicides, for in rotational programs, S39

- Phytophthora capsici, on genetic diversity, 973

- powdery mildew, demethylation inhibiting fungicides, S196

Cucurbit leaf curl virus, Squash leaf curl virus reassortants, clones, S11

Cucurbita spp.

- C. maxima, fungal storage rot, acetic acid as fumigant, S37

-C. pepo, disease management, fungicides and no-till, S27

Cuero, S. P., S101

Cui, K., S20

Culbreath, A. K., S57, S60, S94, S201, S202

Cummings, T. F., S188

Cunfer, B. M., S20

Cuppels, D. A., S1, S19

Curculio caryae, on pecan, entomopathogenic nematodes, S143

Curley, J., S20

Curran, J., S152

Currie, C. R., S108

Curry, K. J., S2, S4, S204

Curtis, R., S15, S39

Cutler, G. C., S132

Cylindrocladium spp., species concepts, rationale, S108

Cytospora spp.

-on cottonwood, canker control in Wyoming, S27

-on Eucalyptus, molecular phylogenetics, S101

Czederpiltz, D. L. L., S20, S108

Czosnek, H., 188

Czymmek, K. J., S162

da Camara Machado, A., S36

da Camara Machado, M. L., S36

da Graça, J. V., S19, S97

Dai, Q., S20

Daleo, G. R., S34
Dallot, S., 159

Dally, E. L., S21

Damann, K. E., S16, S89

Damicone, J. P., S86, S204

Damsteegt, V. D., S20, S59

Dandurand, L. M., S183

Dane, R. A., S54

Dangl, J. L., S159

Daniels, J. L., S20

Darnell, T., S183

da Rocha, A. B., S20, S91

Darocha, M., S132

Darveaux, B., S38, S55

Dastoor, F. P., S108

Daszak, P., S108

Datnoff, L. E., 63, S3, S11, S77, S86

Daughtrey, M., S172, S194

Dauphinais, N., S130

Dautova, M., S21

Davelos, A. L., S21

David, C., S103

Davidovich, M., 741

Davidson, C. R., S21

Davidson, J. M., S76, S108, S110

Davies, K. A., S173

Davis, C. M., S121

Davis, D. J., S121

Davis, E. L., S24, S97, S134, S174

Davis, M., S183

Davis, R. E., S21, S91

Davis, R. F., S132

Davis, R. M., S27, S184

Davis, S. D., S132

Davison, C. R., S24

Dawson, W. O., S74

Day, W., 708

Daykin, M. E., S12

Dean, R. A., 307, S45, S87, S158

de Beer, Z. W., S31

De Boer, S. H., 617

de Capdeville, G., S21, S166, S193

De Cleene, M., 282

Declerq, D., S21, S154

de Cock, A. W. A. M., S123

Deeks, S. J., S183

Dees, R., S143

Défago, G., 873

Degens, B., S82

de Goede, R. G. M., S134

Degooyer, T., S36

de Groot, K. E., 753

Dehne, H.-W., S67

Deibert, E., S46

Deising, H. B., S149

de Jesus Junior, W. C., 1045

de Jong, C. F., S161

Deka, D., 941

de Kock, M. J. D., S161

de la Bastide, P., S181

Delanoy, M., S22

de Ley, I. T., S133

de Ley, P., S133

de Los Reyes, B. G., S65

Delournme, R., 70

Delphinium glaucum, virus infection, Alaska, S76

del Rio, L., S176

de Luna, L., S21

de Meutter, J., S144

den Breeyen, A., S22

Dendy, S. P., S22, S30

Denman, S., S23

Dennis, J. J., S17

Deom, C. M., S4

DePriest, P. T., S127

Dercks, W., S108

Derie, M. L., 606, S42, S184

Derrick, K. S., S47 
Desaulniers, N. L., S123

Desjardin, D. E., S111, S120

Desjardins, A. E., S124, S170

De Souza, W., 408

Desvoyes, B., S27

Dettmena, J. R., S114

Devaux, M., 900

de Waard, M. A., S161

de Werd, H., S52

de Wet, J., S22

de Wit, P. J. G. M., S161

de Wolf, E. D., S22

Dezwaan, T., S38, S55, S165

Diab El-Arab, H. G., S23

Diagnosis

- detection kit, bacteria, fungi, viroids, and viruses, $\mathrm{S} 80$

-molecular diagnostics in fields, S37

—problem description, S171

Diaprepes abbreviatus, Phytophthora association, in Texas citrus, $\mathrm{S} 82$

Dias, F. A., 408

Diaz de Leon, S., S183

Dickburt, C., S21, S23

Dicklow, B., S198

Dickman, M. B., S164

Dickson, D. W., S173

Dicymbe spp., forest as habitat for ectomycorrhizal fungi, Guyana, S112

Didymella bryoniae

—azoxystrobin sensitivity, S67

—on cucumber, acquired resistance, S20

-on watermelon debris, recovery, S47

Diers, B. W., S16

Dill-Macky, R., S23, S27

Diner, A. M., S109

Ding, S.-W., S162

Ding, X. S., 440, S162

Dinkins, R. D., 831

Dinoor, A., 143, 621

Discula destructiva

- population genetics, S127

- seasonal and genetic differences in species, S 81

Disease

—amino acids role, S79

-imaging fungal pathogens, trends, S162

Disease detection, Smart Cycler, Tilletia indica and Phakopsora pachyrhizi, S29

Disease dynamics, tall-grass prairies, prescribed burning effect, $\mathrm{S} 179$

Disease incidence, spatial hierarchy, scale effect, S157

Disease management

— gray leaf spot on turf, control, S148

— peach rusty spot, biological/biorational, S30

- site specific, S167

Disease resistance, mitogen-activated protein kinase pathway, Oxycom treatment, S98

Disease severity, computer program to quantify, S179

Disease susceptibility, host cell death relation, S98

Disease warning system, weather data in Midwestern United States, site specific estimates, S94

Ditylenchus dipsaci, seed dissemination, in Turkey, S138

Diversity measurements, confidence intervals and statistical comparisons, S31

Dixon, E., S92

Dixon, K., S2

Dixon, P. M., 659, 477

Djonovic, S., S23

Docampo, D., S71

Dodd, S. L., S109

Dodds, A., S183

Dodgen, B. J., S23, S70
Dogwood (see also Cornus florida)

- leaf pathogens, characterization, S201

- powdery mildew, diagnostic tools, S202

Doke, N., S86

Dombek, D. G., S142

Domier, L. L., S39, S58, S129

Dominiak, J. D., S24

Donald, P. A., S130, S133

Donaldson, R., S14

Dong, X., S159

Dooham, F., S3

Dopkins, D. M., S36

Dorner, J. W., S112

Dorrance, A. E., S180

Doster, M. A., S24

Dou, H. T., S99

Douches, D. S., S50

Doughty, D. M., S176

Douglas fir

-Rhabdocline infection, detection, S13

-Rhabdocline needle cast, susceptibility, S182

Douhan, G. W., 232, S24

do Vale, F. X. R., 1045

Downer, A. J., 839, 847

Doxtader, D. C., S52, S178

Draper, B. B., S169

Draper, E., S15

Draper, M. A., S177

Drath, M., 941

Draughon, F. A., S15

Drechslera bromi, D. tritici-repentis compared

to, differential medium, S2

Driskel, B. A., S151

Droby, S., S155

Dry, I. B., S28, S194

D'Surney, S. J., S157

Du, W., S24

Duan, C.-H., S24

Duarte, V., S68, S77

Dube, B. N., S133

Dubose, V. B., S47

Duffus, J. E., 797, S150

Duffy, B., 873

Dugan, F. M., S109

Duncan, G. H., S51

Duncan, K. E., S162

Duncan, L. W., S133, S137

Duncan, R., S79

Dunham, S. D., S106, S109

Dunham, S. M., S109

Duniway, J. M., S36

Dunkle, L. D., 648, S24, S52, S81

Durrant, W. E., S159

du Toit, L., S35

Dutra, P. M. L., 408

Dwinell, L. D., S25

Dyer, A. T., S25

Dyer, P. S., S24

Eagen, R. M., S185

Earl, H. J., S132

Eastburn, D. M., S39, S58, S169

Eastman, C. E., S16

Eastwell, K. C., 268, S71

Eayre, C. G., S25

Ebel, R. C., S60

Eberlein, C. V., S183

Ecevit, O., S138

Eckhardt, L., S25

Ecology

-epidemiology, scale, S157

—epidemiology, time and space, S157

Ectomycorrhizae

-morphotypes in spruce/Frasier fir and hardwood forests, S103

—on native oak, diversity, S126

-patterns in pinaceous ecosystems, S163

-sporocarps, nitrogen isotope ratio, S125
Edema, R., S25

Edgar, R. E., S133

Edmonds, R. L., S125, S183

Edmunds, B. A., S25

Edwards, D. I., S144

Edwards, K. J., S185

Effertz, R. J., 572

Egal, S., S171

Egan, J. D., S25, S165

Egel, D. S., S26

Egerton-Warburton, L. M., S117

Eggers, J., S72

Eichhornia crassipes, fungi association, South Africa, S22

Eide, J., S94

Eisenback, J. D., S146

Eizenga, G. C., S44

Ek, B., S149

El Araby, E. M., S51, S177, S178

Elad, Y., 621

El-Allaf, S. M., S26, S139

Elazegui, F. A., S79

El Bassam., S., 782

Elfving, D. C., 673

El Ghaouth, A., S155

Electron microscopy, scanning transmission, cold field emission, pathogen and fungicide residue identification, S50

Ellingboe, A. H., S26, S176

Elliott, M., S183

Ellis, M. A., 336, S26, S27, S66, S171

El-Meleigi, M. A., S26, S109

Elmer, P. A. G., S18

Elmer, W. H., S26, S94, S110, S194

El-Zawahry, A., S119

Emericella nidulans, cleistothecium development, ultrastructure, S124

Emerson, R. W., S187

Endophyte, airborne spore transmission, S116

English, J. T., S53, S56

Ens, W., S80

Enterobacter spp.

-E. cloacae, biocontrol agent, shelf-life factor, S180

-E. intermedium, from grass rhizosphere, antimicrobial effect, $\mathrm{S} 80$

Entomophaga aulicae, cytoskeleton function, S163

Environment, indoor, fungus detection, S170

Epelman, G., S40

Epichloe spp., on grass, fly symbiosis, S117

Epidemiology, mathematical models and patterns, 1001

Epstein, L., S149

Erickson, M. L., S26

Ericson, L., S127

Eriksen, L., 240

Erincik, O., S26, S27

Errata

—vol. 90, no. 10, 2000, 1018

- vol. 91, no. 1, 2001, 228

- vol. 91, no. 3, 2001, 519

- vol. 91, no. 9, 2001, 831

Ersoy, A., S6

Erwinia spp., on ornamentals, irrigation and stormwater runoff sources, S66

-E. amylovora: on apple, Cornell-Geneva rootstock resistance, S66; on apple and pear, spatial and temporal attributes, S67; strains in Turkey, characterization, S90; strains resistant to antibiotics and copper, in Turkey, S6; streptomycin resistance, in Utah, $\mathrm{S} 88$

-E. carotovora: on callas, phosphate effect, $\mathrm{S} 32$; on pepper, stem and peduncle canker, S182; quorum sensing, mechanism, S160; soft rot induced using mineral oil, S53

-E. pyrifoliae: on Asian pear, temperature and $\mathrm{pH}$ effect, S82; molecular analysis, in Korea, S4 
-E. stewartii: on corn, seed and seedling transmission rates, S62; on sweet corn, trait loci, 293

Erysiphe graminis, on wheat, peroxidase gene, S183

Escopalao, V. E., 1054

Escovopsis spp., agarics, ants, and actinomycetes, symbiosis, $\mathrm{S} 108$

Esker, P. D., S166, S177, S179

Eskridge, K. M., S2, S123

Estes, A., S77

Estevez de Jensen, C., S27, S177

Eucalyptus spp.

- mulch, biocontrol of Phytophthora cinnamomi by, 847

-Mycosphaerella leaf blotch, in South Africa, S41

— pink disease, in South Africa, S78

- stem canker, isolate characterization in South Africa, 628

Eujayl, I. M., S64

Eulgem, T., S159

Eutypa lata

- on grape, in California, S89

-PCR-RFLP method to identify, S77

Evans, A. A. F., S35

Evans, C. K., S27

Evans, K., S167

Evans, R. R., S202

Evans, T. A., S21, S24

Everts, K. L., S27, S100

Ewalt, J., S157

Ewart, E. E., S27

Exserohilum turcicum

-on sorghum, crop mixture effect, 720

—on sweet corn, trait loci, 293

Facteau, T. J., S190

Faghihi, J., S130, S133

Fajardo, J. E., S27

Falcon, Y. V., 956

Falk, B. W., S55, S81, S152

Fallah, P. M., S110

Fallon, D. J., S133

Fan, W., S159

Farahat, A., S133

Farman, M. L., S110

Farr, D. F., S105, S164

Farrar, J. J., S27, S184

Faure, S., S7, S27, S162

Fay, P. A., S22

Febres, V. J., S67

Fedak, G., S183

Felcher, K., S50

Felix-Gastelum, R., 1156

Felts, D., S187

Feng, F., 769

Fenton, J., S2

Fermin, G., S28

Fernandez, F., S163

Fernández-Pavía, S. P., S28

Fernando, W. G. D., S28, S99

Ferree, D. C., S26, S27

Ferreira, S., S168

Ferris, H., S134, S146

Ferris, J. M., S130, S133

Ferris, V. R., S133, S142

Ferro, A., S157

Fichtner, E. J., 1092

Ficke, A., 948, S28, S166, S194

Figueroa, A., S90

Filgueira, J. J., S32

Filho, A. B., 1045

Filion, M., S28

Filip, G. M., S186

Firrao, G., 617

Fischbein, C. B., S110

Fitt, B. D. L., 392

Flanagan, S., S39
Flanagan, S. R., S98

Flax, Sclerotinia sclerotiorum on, in Canada, S188

Fletcher, J., S8, S11

Fleysh, N., 941

Flier, W. G., 882

Flint, J., S171

Flor, J. M., S49

Flores, H., S186

Flowers, J. L., S28

Floyd, R. M., S134

Fofana, B., S194

Fogel, R., S101

Fogg, M. L., S28, S194, S195

Folimonov, A., S162

Folkertsma, R. T., 753

Forbes, G. A., 993

Forest

—disease spatial distribution, S156

-epidemics, spatial molecular analysis, S156

-management, tree decay fungi, S20

- pathogen dynamics and human influence, in

Mexico, S155

—production, disturbance agents, S156

- slime molds, Hawaii and the Smokies, S163

Förster, H., S29, S184

Forster, R., S188

Fortnum, B. A., S29, S86, S202, S203

Foster, K. A., S51

Fournier, Y., S130

Fowler, J. M., S95

Fox, A., S167

Fraaije, B. A., 1166

Fraedrich, S. W., S29

Fragaria spp. (see also Strawberry)

- Strawberry mottle virus and Strawberry mild yellow edge virus characterization, detection, S88

Francl, L. J., 572, S2, S29, S30, S58, S175, S177, S179

Frank, S., S38, S55

Frankland, J. C., S121

Franklin, L., S14

Frankliniella spp.

- F. fusca, overwintering in weeds, Tomato spotted wilt virus infection, 891

- F. occidentalis, Tomato spotted wilt virus in, receptor regulation, $\mathrm{S} 26$

Franz, A. W. E., S29

Fravel, D., S5

Fraxinus chinensis, ash yellows, in Columbia, S32

Fray, R. G., S160

Frederick, R. D., S29, S79

Freeman, S., 586, 986, S103

French, C. J., S29

French, J. V., S82, S203

French, R., S29, S85

Friedmann, M., 1209

Friesen, T. L., S29, S30

Frohberg, R. C., S84, S179

Fry, W. E., 882, 1189, S4, S28, S33, S153

Frye, R. J., S66

Fuchs, J. M., S144

Fugiel, J. A., S30

Fujisawa, I., 1149

Funck Jensen, D., 527

Fungal inventory, in Costa Rica, S163

Fungi, preservation, laboratory techniques, S120

Fungicides (general) (see also Fungicides, specific)

- adjuvant chemistry, effect, S31

- apple scab, powdery mildew, cedar apple rust, and quince rust control, S197

-biopesticide evaluation, risk, soil pathogens of bedding plants, S55

-Botrytis cinerea resistant to, instability, 307

- corn gray leaf spot, profitability in use, 477

— downy mildews on rose and snapdragon, S194 -fungal transporters in secretion of toxins, S161

- pathogen metabolite for disease control, S187

-resistant isolates, apple scab, 776

-for Sclerotinia sclerotiorum on lettuce, biocontrol comparison, 221

-strobilurin-based, vegetable crop foliage disease control, S63

- tiered system, discovery, S30

-yield and dose relation, predictability, 708

Fungicides (specific) (see also Fungicides, general)

-Agri 50, pest management tool, S84

- chlorine dioxide, inorganic ion and $\mathrm{pH}$ effect, S18

-Cuprofix Disperss, for perennial and annual crops, S77

-mefenoxam, Phytophthora capsici insensitivity to, dynamics, 553

-metalaxyl, carrot cavity spot control, S184

-myclobutanil, apple scab, resistant strains, 102

-Pyraclostrobin, update, S5

-quinoxyfen: mechanism of action, signal transduction, S34; powdery mildew control in several crops, S64

—-serenade, squash powdery mildew, S98

- strobilurin, powdery mildew and downy mildew of cucumber, resistance, 1166

Funnell, D. L., 92, S59

Furman, L. A., S30, S194, S195

Fusarium spp.: apicidin toxin, duckweed effect, 1141; fusaric acid production, regulation, S51; on onion, electrophoresis, in Egypt, S119; on orchids, physiological characterization, S94; on pea, root inoculated with nonpathogenic isolate, cover photo, August; phylogenetic species concept, S151; species diversity and genetic variation, in prairie grasses, S54; on wheat and barley, head blight, mist-irrigation effect, S27

-F. culmorum, antifungal peptides, in wash fluid, S13

- F. graminearum: head blight and DON production, correlation, S84; population genetic analysis, S122; virulence factor, common with Cochliobolus, S56; on wheat and barley residue, burning effect, S23; on wheat and barley, fungicides and severity, S177

-F. hostae, on hosta and hyacinth, gene genealogy, 1037

-F. oxysporum: on chickpea, molecular variability, S6; on chickpea, temperature and inoculum effect, 807; on cotton, multigene genealogies, race inference, 1231; on gladiolus, genetic diversity, S16; on leafy spurge, transformation for green fluorescent protein, S61; on melon NBS-LRR R-gene homologues, S45; monoterpene, antagonism, S61; on onion, vegetative compatibility groups, $\mathrm{S} 87$; on pea, defense-related mechanisms, cytology, 730; on tomato, biocontrol strains, 449; on tomato, dissemination, S76; on tomato, population in Florida, S5; transformation mediated by Agrobacterium, mutagenesis and gene transfer, 173; on watermelon, resistance, fumigation, and biocontrol, S100

-F. polyphialidicum, diversity, S110

-F. proliferatum: biocontrol agent for grape downy mildew, 1062; laccase production, S51

-F. redolens, gene genealogies, phylogeny, 1037

-F. solani: on muskmelon, pectolytic enzymes and virulence, S99; on soybean, differential gene expression, S113; on soybean, mycovirus detection, S58

-F. subglutinans, on corn, seed transmission and systemic infection, $\mathrm{S} 95$

$-F$. verticillioides: on corn, seed infection and yield effect, S98; on corn, seedling infection, S32

Futai, K., S184 
Gabler, J., S108

Gabriel, D. W., S152

Gadoury, D. M., 948, S28, S47, S194

Gaerber, U., S108

Gaeumannomyces graminis on wheat

—epidemics and yield loss, 694

-manganese oxidizing factor, S88

Gagné, P., 369

Gallagher, R., S82

Gallian, J. J., S184

Gal-On, A., 565

Galwey, N., S82

Gamboa, J. S., 956

Ganoderma lucidum, laccase isozymes, characterization, S115

Gao, B., S134

Gao, M., S160

Gao, X., S134

Garand, C., 730

Garay Serrano, E., 882, S33

Garbelotto, M., S30, S76, S108, S110

García, J.-A., 159

Garcia-Pedrajas, M. D., S30, S83, S165

Garcia-Ruiz, H., S30

Gardan, L., 617

Gardens

-school: behavioral and nutritional aspects, S171; curriculum relevance, S171; organization and set up, S171

-youth programs in United States, S171

Gardner, D. E., S3, S48

Garner, D., S69

Garrett, K. A., 993, S22, S30, S31

Garzon, C. D., S31

Gascho, G. J., S201

Gassmann, W., S40

Gates, R. N., 255, S144

Gaudet, D. A., S41

Gaush, P., S79

Gautieria monticola, Suillus suilloides comparison, genet size in Sierra Nevada, S125

Gavaletto, J. R., 1181

Gavassoni, W. L., 534

Gay, P. A., S31, S59, S184, S187

Gazaway, W. S., S138

Gbehounou, G., S168

Gbur, E. E., S142

Gealy, D. R., S44

Geering, A., S45

Geider, K., 511

Geiser, D. M., 173, 1037, S31, S110, S121

Geiss, P., S31

Geldenhuis, M. M., S31

Geletka, L. M., 628

Gene silencing, host protein and virus suppressor, S161

Genetically modified organisms

—attitude in Pacific Islands, S168

-introduction of, attitude in West Africa, S168

— science and politics in Latin America, S168

Genomics

-Phytophthora spp., consortium, S158

-plant pathogen, public funding, S158

Gent, D. H., S31

Genta, J. G., S133

Geranium

-Ralstonia solanacearum, race 3 in Wisconsin, S95

—viruses of, genome organization, S49

Gerats, T., 1069

Gerbera jamesonii, powdery mildew, control in Hawaii, S90

Gergerich, R. C., S65

Gerhard, G., S114

German, T. L., S26

Gernardy, M. G., 268

Gessner, R. V., S42, S124

Gevens, A. J., S149
Ghabrial, S. A., S149

Ghanim, M., 188

Gheysen, G., S141, S144

Ghimire, S. R., S31

Giagnacova, M., S38, S55

Gianessi, L. P., S82

Gibberella spp.

-G. fujikuroi: mating population, cryptic speciation, S124; multiple vic loci, mapping, S99

- G. zeae: ascospore dispersal, dynamics, S58; ascospore survival, plant surface, S44; Bacillus subtilus as antagonist, uridine augmentation, $\mathrm{S} 42$; in corn and wheat stubble, genetic diversity, S43; distribution in Australia and Southeast Asia, S13; environment, ascospores, and inoculum relation, S179; North and South American populations, comparison, S91; overwintered inoculum, spore gradients, S21; yeasts antagonistic to, $\mathrm{S} 80$

Giblin-Davis, R. M., S173

Gierth, K., S135

Giesler, L. J., S100

Gilbert, J., S32

Gilbertson, R. L., S44, S64, S83

Gildow, F. E., S20

Giles, C. G., S80

Gillaspie, A. G., Jr., S202

Gilles, T., 392

Giraud, D. D., S134

Gisi, U., 579, S78

Gitaitis, R. D., S92

Glasheen, B. M., S195

Glass, N. L., S114

Glazebrook, J., S159

Gleason, C., S138

Gleason, M. L., 659, S7, S25, S32, S53, S88, S94

Glenn, A., S32, S98, S110

Glickmann, E., S76

Gliocephalis hyalina, parasite of Fusarium, S114

Globodera spp., Punctodera spp., relation, phylogenetic, S142

- G. pallida, genetics of populations, agricultural practice effect, 753

-G. tabacum, on tobacco, reproduction suppressed, S136

Gloeophyllum trabeum

- quinone reductase from, purification, S73

—on wood, rot epidemic in California, S190

Glomus intraradices, on onion, interaction with Sclerotium cepivorum, $\mathrm{S} 43$

Glycine betaine, in fungi, S103

Godoy-Lutz, G., S199, S200

Godshall, M. A., S33

Goellner, M., S134

Goffinet, M. C., S28, S194

Gold, R. E., S202

Gold, S. E., S25, S30, S83, S165, S203

Goley, E. D., S89

Gommers, F. J., S21

Gong, Y. Y., S171

Gonsalves, D., S28, S71

Gonzalez, M. C., S110

Good, X., 274

Goodwin, S. B., 648, 1181, S1, S32, S88, S152

Gorbet, D. W., S57, S60

Gordon, D. T., S25, S176

Gordon, T. R., S78

Gottwald, T. R., 30, S32

Goverse, A., S143, S147, S174

Gracia-Garza, J. A., S32

Graef, G. L., S100

Grafius, E., S132

Grafton-Cardwell, E., S81

Graham, J. H., 30, S19, S137

Graham, R., S118

Graham, T. L., S175

Granatstein, D. M., 673

Grand, E. A., S110
Grand, L. F., S111

Grape

-Agrobacterium vitis, mutations, 966

—black rot, management, fungicides, S166

-Botrytis bunch rot, latent infection, S100

-Botrytis decay, in storage, $\mathrm{SO}_{2}$ effect, $\mathrm{S} 69$

- downy mildew, fungicide for, $\mathrm{S} 12$

-Fusarium, Cylindrocarpon, and Diplodina pathogens, S34

-leaf and cane infection, Phomopsis viticola cause, S26

-Phaeoacremonium vine decline, hot water treatment, S189

-powdery mildew: biocontrol with Fusarium proliferatum, 1062; cover photo, October; disease management, S166; epidemiology, 948

-replant disorder, methyl bromide, S80

Grapevine leafroll-associated virus, on grape, detection, coat protein, genome, 274

Grass, cuticle, dissolution effect, S146

Grau, C. R., S57, S130, S176, S178, S179

Gravert, C. E., S32

Graves, A. S., S2

Graves, W. R., S61

Gray, F. A., S27, S39, S53, S143, S184, S186

Gray, P. M., S182

Gray, S. M., 792, S54

Greer, C. A., S167

Gremmeniella spp., on conifers, status as causal agents, S195

-G. abietina, on jack pine, ligno-suberized tissue formation, 1128

Grenier, J., S194

Gresshoff, P., S42, S113

Grevesse, C., S154

Grewal, P. S., S136, S137, S143, S144, S173

Grewal, S. K., S173

Griffin, R. L., S153

Griffiths, A. G., S139

Griffiths, H. M., S32

Grisham, M. P., S33

Gritsenko, M. A., S53, S91, S186, S191

Grodzinski, B., S68

Gronwald, J. W., 1141

Groose, R. W., S39

Gross, P. L., S177

Groth, D. E., S33

Groth, J. V., S6

Groundwater, saline, flow-confinement system, S157

Grove, G. G., S188, S192

Groves, C. L., S33, S53

Groves, R. L., 891

Grubisha, L. C., S116, S125

Grünwald, N. J., 882, S28, S33

Gu, Y. H., S33

Guan, J., S167

Guaragna, M. A., S49

Gubler, W. D., S74, S75, S77, S89, S185, S187, S189, S191

Gudmestad, N. C., S177

Guerber, C. A., S93

Guerber, J. C., S18, S33, S55

Guerke, W. R., S201

Guetsky, R., 621

Guevara, M. G., S34

Guggenheim, R., S78

Gugino, B. K., S34

Guilhabert, M. R., S34

Guillon, C., S34

Guixi, H., S47

Gumpf, D. J., S81

Gundersen, B., S184

Guo, B., S34

Gupta, V. S., S6

Gustafson, G. D., S34

Gutierrez, H. E., S111

Gutierrez, W. A., S27, S35 
Guy, P. L., S152

Gwinn, K. D., S61

Ha, T. N., S13

Ha, Y.-S., S164

Haas, D., 873

Haber, S., S80

Habera, L. F., S75

Hafez, S. L., S134, S135

Hagan, A. K., S13, S35

Hahn, R. L., S181

Haider, M. S., S35

Hale, K., S135, S145

Haley, S. D., S52, S175, S178

Halford, P. D., S167

Hall, A. J., S171

Hall, J. S., S85

Hallen, H. E., S111

Halley, S., S177

Halling, R. E., S163

Hallmann, J., 415, S135, S138

Halloin, J. M., S45, S65

Hamblin, A. M., S35, S148

Hameed, K. M., S35

Hamel, C., S28, S34, S44

Hamelin, R. C., 249, 369, S156, S193

Hamer, J. E., S120, S165

Hamer, L., S38, S55, S165

Hamilton, C. Y., S202

Hamm, P. B., S35, S136

Hammerschmidt, R., S20, S50, S71, S91

Hammond, B., S36

Hammond, J. (Md.), S36, S99

Hammond, J. M. (N. Dak.), S84

Hammond, R. W., S36, S99

Han, B., S159

Han, L., S36

Han, Y., S139

Handoo, Z. A., S131

Hanlin, R. T., S110

Hansen, D. R., S191

Hansen, E. M., S191

Hansen, J. M., S84, S178, S179

Hanson, L. E., S36, S40, S95

Hänßler, G., S12

Hao, J. J., S36

Harasawa, R., S42

Harbin, M., S111

Harding, M. W., S36

Harkness, J., S111

Harmon, P. F., S148

Harrington, G., S65

Harrington, T. C., S4, S127, S151

Harris, T. S., S139

Harrison, K. J., S113

Harrison, L. M., S185

Hartin, J., S90

Hartman, G. L., S32, S39, S55, S175, S176

Hartman, J. R., S28

Hartung, J. S., 599, S7, S40

Harveson, R. M., S36

Harvey, T. L., S80

Hash, C. T., S169

Hashiba, T., S187

Hashmi, R. Y., S37

Haskins, E. F., S106

Hassanein, F. M., S37

Hatakeda, K., 181

Hau, B., 1045

Hausbeck, M. K., 553, 973, S166, S195

Hauschild, R., S37

Häuser-Hahn, I., S12

Haware, M. P., S6

Hawes, M., 820

Hawkins, L. K., S37, S111

Hawksworth, D. L., S164

Hay, F. S., S17, S37

Hayes, S. A., S112
Haymes, K., S37, S80

Haynes, J., S72

Hazir, S., S135

He, C. Y., S184

He, S. Y., S160

Heald, T. E., S39

Heath, R. N., S78

Hebbar, K. P., S10

Hebbar, P. K., S79

Hedden, R. L., S45

Hedjaroude, G. A., S1

Heick, J., S183

Heidel, G., S84

Heidenreich, G. E., S37

Heidenreich, M. C., S37

Heiman, D. F., S30

Hein, G. L., S85

Heine, G., S72

Heiniger, R., S38, S55, S165

Heist, E. P., 1224, S38

Held, L. J., S143

Helder, J., 753, S174

Hell, K., S38

Heller, J. J., S77

Helliot, B., S38

Helm, J. H., S191

Helminthosporium victoriae, virus infection, molecular basis, S149

Helms, T. C., S179

Hemerocallis spp., leaf rust, in Georgia, S95

Hemmes, D. E., S111, S163

Hendricks, J. R., S135

Henk, D. A., S112

Henkel, T. W., S101, S112, S125

Hennig, F., S108

Henry, M., 55

Henry, S. H., S170

Herbert, D. A., S81

Herlache, T. C., 966

Herms, D., S15

Hernandez, A., S38

Hernandez, J., S161

Hernandez, R., S63

Hernick, C. A., S122

Herpetomonas spp., trypanosomatid parasite, phosphatase activity, 408

Herr, J. R., S112

Herrera, J., S112

Herrera-Estrella, A., 687, S168

Herron, C. M., S97

Hershman, D. E., S130

Hert, A. P., S38

Hervás, A., 807

Hess, N., S25, S93, S204

Hesterberg, D. L., 1092

Heterodera spp.

$-H$. avenae, on wheat, nematicide effect, yield, S129

-H. glycines: classification scheme, S139; Hirsutella minnesotensis parasitic on juveniles, S138; inbred lines, characterization, S132; lime-stabilized municipal biosolids for control, $\mathrm{S} 145$; on soybean, abnormal males on roots, $\mathrm{S} 132$; on soybean, population dynamics in United States and Canada, S130; on soybean, reproduction on resistant germ plasm, S139; parasitic ability, AFLP analysis, S129; spatial distribution, geostatistical tools, S130; tillage and spatial pattern, relation, 534

-H. schachtii: soil suppression, effect on sexes, S134; on sugar beet, tolerance, S135

Heteroderidae, taxonomy and host specificity, S143

Heterorhabditis marelatus, on Colorado potato beetle, management, $\mathrm{S} 132$

Heuchelin, S. A., S39

Heungens, K., 383

Hewlett, T. E., S135
Hibbett, D. S., S102, S164

Hibi, T., 377

Hibiscus rosa-sinensis, virus detection in, S2

Hiebert, E., S71

Higgins, B., S175, S199

Highland, H. B., S39

Hilgren, J., S40

Hill, A., S36

Hill, R. A., S18

Hillman, B. I., S149, S195, S196

Hinkle, N., S141

Hinton, D. M., S4, S32, S98

Hintz, W. E., S181

Hiradate, S., 181

Hiremath, S. T., S10

Hirsch, J. C., S114

Hirsutella spp.

-H. minnesotensis, nematode hosts, S138

-H. rhossiliensis: nematode parasite, biocontrol, 324; nutrition requirements, S118

Hiruki, C., 546

Hix, L., S12

Hjeljord, L. G., 1172

Ho, H. H., S99

Hobbs, H. A., S39

Hoch, H. C., S163

Hodge, K. T., S125

Hodgkiss, I. J., S31, S114, S125

Hoepting, C., S39

Hoffman, L. E., S166

Hoffman, L. M., S34

Hofmann, N. E., S35, S148

Hogenhout, S. A., S15, S31, S99, S176

Hogue, R., S44

Hoitink, A. J., 1116

Hoitink, H. A. J., S19

Holbrook, C. C., S57

Holeva, R., S39

Holleran, H. T., S66

Hollingsworth, C. R., S39, S53, S184

Hollomon, D. W., 1166, S34

Holm, A., S67

Holmes, G. J., S39

Holt, J., 720, 924

Holub, E. B., S159

Holzman, K. M., S114

Homobasidiomycetes, corticioid, evolution, S164

Honda, K., S2

Honda, Y., S43

Hong, C. X., S5, S40

Hong, S., S45

Hopkins, D., S40

Hops, viruses, spatial distribution in Washington, S71

Horak, E., S107

Horita, H., S60

Horita, M., 399

Horn, B. W., S112

Horowitz, S., 986

Horst, K., S72

Horton, D. L., S52

Horton, T. R., S163

Hosaka, K., S112

Hoskins, A. J., S40, S131

Hosokawa, D., 1149

Hosta, bacterial soft rot, cold storage effect, S69

Hotchkiss, M. W., S75

Hou, Q. M., S44

Hou, Y.-M., S44

Hounsa, A., S171

Howard, R. J., S14, S41, S162

Howell, C. R., S40, S95

Howie, W. J., S61

Hoy, M. W., S56

Hoyos, M. E., S40

Hsiang, T., S39, S40, S43

Hsieh, H.-M., S112

Hsu, H. T., S17 
Hu, C. C., S17

Huang, J. K., S124

Huang, Q., S40

Huarte, M., S34

Huber, B., S12, S78

Huber, D. M., S41, S88

Huber, L., S78

Hückelhoven, R., 127

Hudelson, B., S95

Hue, N. V., S136, S142

Huff, D. R., S148

Hughes, G. R., S190

Hughes, G., 30, S157

Hughes, K. W., S110, S116

Hughes, P. L., S41

Hughes, R. H., S187

Hughes, T. J., S178

Huhndorf, S. M., S119, S163

Hui, E., S136

Hummel, R. L., S18

Hum-Musser, S. M., S65

Humulus lupulus

-Fusarium cone tip blight, S9

-nematodes, Tasmania, S37

- powdery mildew, Serenade as biocontrol agent, S190

Hung, Y.-C., S12

Hunter, G. C., S41

Hur, J. H., S4, S82

Hurchanik, D. R., S136

Hurtt, S., S56

Hussey, R. S., S134, S161

Huyck, E., S141

Hwang, C. F., S147

Hwang, H., S49

Hwang, J., S41

Hwang, S. F., S14, S41

Hyakumachi, M., 1054, S118

Hyde, K. D., S31, S104, S113, S114, S120, S124, S125

Hydnellum spp., morphological and pigment characteristics, S126

Hydrangea, powdery mildew and Cercospora leaf spot, Heritage 50W for control, S35

Hyman, B. C., S131

Hymenogaster sublilacinus, panmixia in, conifer biogeography, S101

Hymes, M., S10, S86

Hymowitz, T., S176

Hyphomycetes, dematiaceous, freshwater, Hong Kong, S125

Hypovirulence, RNA hypovirus, for Cryphonectria canker on eucalyptus, 628

Hypovirus, engineering, applications, S150

Hysterangium spp., molecular phylogenetics, S112

Hywel-Jones, N. L., S103

Ibanez, A., S188

Ibrahim, A. M., S52

Idris, A. M., S11, S41, S42

Ierulli, J. M., S42

Im, Y. J., S42

Impatiens necrotic spot virus, on peanut, in Georgia, S94

Imperata cylindrica, biocontrol with fungi, S97

Inderbitzin, P., S111, S113

Infection, extracellular matrix, function, S148

Information technology, GIS/GPS based, crop decision in California, S167

Ingelbrecht, I., S161

Ingham, R. E., S136

Inglis, D. A., 606, S42, S72, S184

Ipomoea aquatica, diseases, Ontario and California, S14

Iqbal, M. J., S42, S113

IR-4 project, fungicide and nematicide registration update, $\mathrm{S} 88$

Irrigation, Phytophthora and Pythium in potted plants, recirculating system, S188

Ishiguro, K., 316, S2, S42

Ishii, H., 1166

Islam, S. Z., S4, S42, S43

Ismail, M. A., S99

Iten, L. B., S80

Itersonilia perplexans, host, experimental and natural, S60

Ivey, M. L., S19

Izaguirre, M. L., S79

Jabaji-Hare, S. H., S28, S34, S44, S195

Jackson, L. E. (Ark.), S142

Jackson, L. (Calif.), S16

Jackson, T. A., S43

Jacobi, W. R., S47

Jacobs, K., S113, S114

Jacobsen, B. J., S5, S100

Jacobson, A. L., S144

Jacobson, D. L., S114

Jaffee, B. A., 324

Jagdale, G. B., S136

Jaime, M. D. L. A., S43

Jaime-Garcia, R., 1156, S19, S43

Jamai, A., S147

James, D., S43

James, T., S105, S114

Janisiewicz, W. J., 1098, S7, S43, S55, S154

Jansson, H.-B., S149

Jaramillo, R. E., 993

Jarosz, A. M., S43, S77

Jarret, R. L., S16

Jasalavich, C. A., S44

Javier, D.-U., S114

Jaworski, A., S98

Jeannotte, R., S44

Jeewon, R. V., S114, S124

Jeffers, S. N., 307, S24

Jeger, M. J., 392, 1001

Jelkmann, W., 261, S88

Jellison, J., S44, S73

Jernstedt, J., S11

Jeuffroy, M.-H., 694

Jia, Y. H., S44, S148

Jiang, G., S165

Jiang, H., S44

Jiang, T., S90

Jijakli, M. H., 1030, S8, S15, S21, S22, S23, S38, S85, S154

Jiménez-Díaz, R. M., 807

Jin, S. L., 680

Jin, Y., S44, S68

Joardar, V., S159

Johansen, L. K., S161

Johnson, C. S., S136

Johnson, D. A., S46, S72, S188

Johnson, D. J., S45

Johnson, K. B., 1214, S45, S86, S87, S190

Johnson, W. C., S66

Johnston, P. R., S124

Johnston, S. A., S28, S194, S195

Jolley, L., S45, S83

Jomantiene, R., S91

Joncheray, G., S77

Jones, A. L., 102

Jones, A. T., S45, S51

Jones, D., S84

Jones, J. (La.), S25, S93

Jones, J. B., S16, S38

Jones, J. T. (UK), S15, S174

Jones, M. S., S108

Jones, M. W., S178

Jones, R. K., 821

Jones, S., S165

Joobeur, T., S45

Joosten, M. H. A. J., S161

Jordan, R., S49

Josefsson, C., S29
Joshi, B., S8

Ju, Y.-M., S112

Jugmohan, M., S185

Julian, A. M., 149, 720

Jung, G., S20, S45, S121

Jung, H. S., S117

Jurgenson, J. E., S99

Justesen, A. F., 527

Juvik, J. A., 293

Juzwik, J., S185

Kabir, Z., S45, S114

Kachroo, P., S45, S159

Kado, C., S38

Kadooka, C. Y., S90

Kageyama, K., 1054

Kakani, K., S150

Kakizawa, S., 1024

Kaloshian, I., S136, S144

Kalsbeck, S., S52, S178

Kammenga, J. E., 753

Kanaan-Atallah, Z., S46

Kanda, E., 316

Kanematsu, S., S2

Kaneshiro, W. S., S46

Kang, B. R., S51

Kang, J.-C., S107, S108

Kang, S., 173, S148

Kang, W. S., S49

Karanastasi, E., S46

Karasev, A. V., S46

Karp, M. A., S46

Karr, A., S56

Karssen, G., S133

Kasschau, K. D., S161

Kassemeyer, H.-H., S12, S78

Katan, J., S76

Kaufman, H. W., S146

Kawakita, K., S86

Kawamata, H., S187

Kaya, H. K., S133, S135

Kayim, M. K., S47

Kazmierczak, P. K., S47, S150

Kearns, H. S. J., S47

Keinath, A. P., S47

Kelemu, S., S47

Keller, B., 55

Keller, K. E., S58

Kelly, C., S47

Kema, G. H. J., 1181

Kennedy, G. G., 891

Kennedy, L. K., S77

Kennelly, M. M., S47

Kenney, M., S115

Keskin, N., S135

Keuck, A., S108

Keudell, K. C., S124

Khairallah, M., 55

Khalilian, A., S139

Khan, A. (Calif.), S185

Khan, A. A. (India), S136

Khan, M. F. R., S48

Khan, M. S. A., S129

Khan, N. I., S48, S80

Khan, Z., S136

Khangura, R., S48

Kharbanda, P. D., S185, S191

Kieu, N., S43

Kilic, O., S48

Killgore, E. M., S48

Killigrew, B. X., S48

Kim, B. V., S46

Kim, D. H., S47, S48, S74, S84, S188

Kim, H.-W., S115, S116

Kim, K. C., S51

Kim, K. R., S49

Kim, K. S. (Ark.), 165

Kim, K.-S. (Iowa), S32, S94 
Kim, K. W., 165, S49

Kim, K. Y., S80

Kim, M.-S., S156, S202

Kim, P. G., 165

Kim, S. G., S49

Kim, S. H., S8, S49, S56, S93, S185, S186, S191

Kim, Y. C., S42, S48, S49, S51, S80

Kim, Y. H., 165, S115

Kinard, G., S49

Kinesin, motor proteins in fungi, evolution, S123

King, P. S., S137

King, S. B., 720

Kinkel, L. L., S21, S49, S54, S95, S158

Kinkema, M., S159

Kinscherf, T. G., S49

Kiraly, L., S14

Kirisits, T., S113

Kirk, W. W., S50, S81

Kirkpatrick, B. C., S34, S79, S152

Kistler, H. C., S122

Kitada, K., 316

Kitchen, N. R., S133

Klassen, G. R., S123

Kleifeld, O., 687

Klein, J. H., S37

Klein, M., 741

Klein, R., S9

Kleinhenz, M., S180

Kleinkopf, G., S83

Kleinschmidt, C. E., S50, S115

Klerks, M. M., 1085

Klessig, D., S45, S159

Klich, M. A., S115

Kline, W. L., S28, S194

Klingeman, W. E., S3

Kloek, A., S159

Kloepper, J. W., 593

Klopfenstein, N. B., S156, S202

Klose, J., S165

Klubek, B. P., S70

Kluepfel, D. A., S86, S202, S203

Kluyveromyces marxianus, oleic acid conversion by, $\mathrm{S} 124$

Knight, L. M., 1149

Knight-Slater, D. F., S189

Knowles, K., S156

Knudsen, G. R., 301, S181

Ko, E. M., S115

Kobayashi, D. Y., S8, S28, S75, S194

Kobayashi, T., 316, S42

Kobbeman, K., S19

Kobiler, I., 143

Kobresia myosuroides, mycorrhizal association, S122

Koch, D. W., S39, S143, S184

Koch, E., S184

Koehler, K. J., S94

Kogel, K.-H., 127

Köhl, J., 485

Kohl, R., S68

Kohn, L. M., S107, S115

Koike, S. T., 797, S14, S17, S76, S150

Kokalis-Burelle, N., S2, S168

Köller, W., 776

Komolong, B., S50

Komorek, B. M., S50

Konrad, T., S68

Konuru, H. B., S115

Koppenhofer, A. M., S135

Kopp-Holtwiesche, B., S135

Koprowski, H., 941, S46

Kora, F. E., S137

Korndörfer, G., S77

Korsten, L., S155

Kosta, K. L., S71

Kosted, P., S50

Kotcon, J. B., S50, S135

Kraft, J. M., S191
Krall, E., S142

Krall, J. M., S143

Krause, C. R., S50

Krause, M. S., 1116

Krause, N. J., S102

Kremser, J. J., S8, S195

Kretzer, A. M., S116

Kromroy, K. W., S185

Kronstad, J., S165, S185

Kropp, B. R., S191

Krueger, D., S116

Kruijt, M., S161

Kubota, M., S118

Kuboyama, T., 1024

Kucharek, T. A., 63, S11, S50

Kues, U., S114

Kuldau, G. A., S51

Kumar, J., 127

Kumar, P. L., S51

Kumm, S., S26, S95

Kunkel, B. A., S137

Kunkel, B. N., S159

Kurle, J. E., S27, S51, S167, S177, S178

Kurtzman, C. P., 1098, S43

Kurtzweil, N. C., S176, S178

Kuruppu, P. U., S51, S80

Kuti, J. O., S111, S115, S116, S119

Kwon, C., S74

Kwon, M. K., S51

Kwon, S.-I., S51, S104

Kyuri green mottle mosaic virus, molecular characterization, 565

Labbé, C., S194, S196

Labuschagne, P. M., S195

Lacap, D. C., S113

Laccaria spp., systematics and ecology, Alpine species, S120

- L. bicolor, symbiosis-regulated genes, characterization, $\mathrm{S} 10$

Lachman, O., 565

Lacouture, M. N., S145

Lactarius spp., molecular systematics, S112

Laetiporus huroniensis, L. conifericola comparison, on conifer, $\mathrm{S} 102$

Laflamme, G., 1128, S195

Laing, M. D., S19

Lakshman, D. K., S150

Lalancette, N., 1109, S30, S51, S194, S195

Lam, S. T., S158

Lamari, L., S60

Lambers, H., S85

Lambert, K. N., S130, S137

Lamondia, J. A., S52, S195

Lamour, K. H., 553, 973, S166, S195

Lamppa, R. S., S177

Lan, Z., S52

Lancaster, M. E., S39

Landa, B. B., 807, S52

Landscape

—arid, soil fungal biodiversity, elevational trend, S164

—Ozark, Armillaria spp., S156

—pathology, framework definition, S155

—remote sensing, GIS models, ecosystems, S156

Lane, L. C., S52, S100

Lang, G. A., S188

Lange, R. M., S185

Langham, M. A. C., S52, S175, S178

Lannou, C., 477, 500

Lanoot, B., 282

Lansing, J. L., S117

Lapaire, C. L., S52

Lapidot, M., 1209

Largeteau-Mamoun, M. L., 905, S18

Larkin, R. P., S53

Larsen, R. C., S53, S186, S191

Lartey, R. T., S53
Lasiodiplodia theobromae, on loblolly pine, tip dieback, S45

Lasiosphaeria ovina, phylogeny and morphology, S119

Laskey, J. G., S53

Lathrop, R. G., S167

Latin, R. X., S26, S148

Laureano, S., S116

Lauren, D., S96

Lavi, N., 565

Lawrence, D. M., S195

Lawrence, G. W., S137, S138, S140, S141

Lazarovits, G., 449, S1, S5, S142

Leacock, P. R., S110

Leandro, L. F. S., 659, S7, S53, S88

Leath, S., S37

Lebron, L., S116

Le Cam, B., 900

Lee, C. W., S178

Lee, D.-H., S115, S116

Lee, F. N., S18, S23, S44, S70

Lee, H. K., S137

Lee, I.-M., S54

Lee, K., S30

Lee, L., S54

Lee, M. E., S176, S179

Lee, M. W., S98

Lee, N., S165

Lee, R. F., S67

Lee, S. (S. Africa), S116

Lee, S. D. (Minn.), S54

Lee, S.-H. (Korea), S53

Lee, S. W. (Canada), S49, S186

Lee, Y.-R. J., S162

Lee, Y. W., 1141

Leem, Y. E., S115

Legard, D. E., S54, S57, S62

Legendre, B. L., S33

Leggett, G., S37

Lehman, J. S., S65, S93, S180

Leininger, T. D., S54, S62

Lellis, A. D., S161

Leloup, L., S38

Lemna pausicostata, apicidin and HC-toxin effect, histone deacetylase activity, 1141

Lemon (see also Citrus)

-Hyphoderma gummosis, characteristics in California, $\mathrm{S} 58$

Lemos, E. G. M., 599

Lennox, C. L., S54

Lentinula edodes, management in agroforestry, S104

Lentinus tigrinus, circum-global species, S110

Leonard, K. J., S71, S158

Leone, G., 1085

Leong, S., S20

Leoni, C., S68

Leon-Ramirez, C. G., S165

Leotia spp., classification, challenge to, $\mathrm{S} 128$

Lepoivre, P., 1030, S8, S15, S21, S22, S23, S38, $\mathrm{S} 85, \mathrm{~S} 154$

Leptographium spp.: blue-stain agents, S113; on loblolly pine, vectors, S25

- L. wageneri, on pinyon pine, black stain root disease, S47

Leptosphaeria maculans

-on Brassica napus, genetic control and host range, 70

-resistance genes, in nonhost plants, S26

Leslie, J. F., S54, S91, S99

Lester, D. G., S95

Letcher, P. M., S105, S116, S121

Letters to editor

-agricultural biotechnology, food allergens, labeling, and communications, 524

-bacteria, classification and nomenclature, 617

- citrus canker epidemic, Florida, eradication policy, 30 
Lettuce

-bacterial leaf spot, weather factors, S89

- downy mildew, spatial analysis and geostatistics, 134

Lettuce infectious yellows virus, RNA binding activities, S55

Lettuce necrotic stunt virus, on lettuce and tomato, characterization, 797

Leuchtmann, A., S104, S117

Leuck, J. D., S41

Leveleki, L., S165

Leverentz, B., S55, S69

Levesque, C. A., S123, S152, S193

Levin, A., 579

Levy, L., 935, S20, S32, S59

Lewandowski, D. J., 747

Lewellen, R. T., S150

Lewis, E. A., S117

Lewis, E. E., S131, S140

Lewis, S. A., S86, S203

Li, B.-Y., S5

Li, G. H., 680

Li, L. (Ind.), S117

Li, L. P. (Singapore), S44

Li, S. D., S32, S55

Li, X., S159

Li, Y. H., S137

Liang, J., S13

Lian-Hui, Z., S160

Lichens

-concept, S164

-symbiosis, evolution, S118

Lichens-Park, A. E., S158

Liew, E. C. Y., S31, S113, S114, S124

Lightfoot, D. A., S42, S113, S147, S169

Lilleskov, E. A., S163

Lim, C. K., S4, S82

Lim, Y. W., S117

Lin, H.-X., S152

Lin, S.-S., 856

Lin, X. R., S117, S123

Lindahl, A. E., S117

Lindemuth, R., S117, S118

Linder-Basso, D., S196

Lindner, J. L., 1085, S88

Lindow, S. E., 415, S154

Line, R. F., S16, S97, S182

Ling, Q., S174

Lipps, P. E., S22, S24

LiPuma, J. J., S63, S173

Lisianthus, fabavirus from, characterization, S17

Little cherry disease virus, diagnostic test, ELISA based, $\mathrm{S} 87$

Little cherry virus, on sweet and sour cherry, detection, 261

Little, R. S., S52, S178

Littlefield, L. J., S151

Liu, B., S55, S162

Liu, C., S150

Liu, H. Y., 797, S55, S150

Liu, L. X., S174

Liu, Q., S138

Liu, S. F., S138

Liu, X. Z., S55, S118

Livieratos, I. C., S55

Llave, C., S161

Lo, C., S38, S55, S165

Locke, J. C., S55

Lockhart, B. E. L., S45, S56

Lodge, D. J., S118

Lodge, J. D., S116

Löffel, K., S12

Logrieco, A., S54

Loke, J. B., S101

Lolium perenne

- gray leaf spot, assay for pathogen, S90

-leaf spot resistance, QTL mapping, S20

— stem rust, moisture duration, S72
Lommel, S. A., S89

Long, D. L., S16

Longcore, J. E., S108, S121

Longer, D. E., S65

Longidorus spp.

-on loblolly pine seedlings, stunting association, S29

-morphological and molecular taxonomy, in Arkansas, S146

Longstreth, D. J., S103

Loper, J. E., 593, S86, S87, S190

Lopes, A. H. C. S., 408

Lopes, D. B., 212

Loppnau, P., S56

Lotrakul, P., S56

Louie, R., S178

Louws, F. J., S1, S18

Lovic, B., S40

Lozoya-Saldaña, H., 882

Lu, S.-W., S56

Lucas, J. A., S185

Lucas, P., 694

Luce, K., S56

Lucio-Zavaleta, E., 792

Luderer, R., S161

Ludy, R., S184

Lumbsch, H. T., S117, S118

Lumsden, R. D., S10, S79

Lumyong, P., S104, S120

Lumyong, S., S104, S120

Lundeen, P., S97

Lundquist, J. E., S155, S156

Luo, Y., 665, 759, 864, 1197, S9, S56, S57

Luong, L. T., S141

Lupinus nootkatensis, virus on, in Alaska, S189

Luster, D. G., S20, S59, S61

Lutzoni, F., S118, S128

Lycopersicon peruvianum (see also Tomato)

-nematode resistance gene, in leaves and roots, S144

Lynch, R. E., S34

Lyons, M. T., S57

Ma, X., S40

Ma, Z., 428, 665, S9, S57, S103

Mabagala, R. B., S64

MacDonald, E., S121

MacFarlane, S. A., S10, S46

MacGuidwin, A. E., S68, S130

Machado, C., S123

Machado, M. A., 599

Machardy, W. E., S17

MacKenzie, S. J., S57

Maclura pomifera, extracts, antifungal activity, S115

Macromycetes, saprotrophic, diversity in Guyana, S101

Macrophomina phaseolina

- host specialization, marker for corn, cotton, sorghum, soybean, 120

-on soybean, herbicide effect, S40

- toxins, guayule extract effect, S116

Macroptilium mosaic virus, A and B components, molecular characterization, S42

Madden, L. V., 336, 1116, S22, S26, S27, S66, S78, S157

Maes, L., S186

Maffia, L. A., S64, S86, S119

Magan, N., S155

Magarey, P. A., S47

Magnaporthe grisea

-appressorium formation, Ste12 homologue, S120

-Cla4 homologue, characterization, S117

- gene disruptions, S38

- genome project, blast off, S158

- genome-scale gene identification, function analysis, S55 -ketoreductase ORF analyses, S36

- in leaves, quantification using PCR, S73

- mating type determination, PCR assay, S203

- perennation, disease management, S148

-on perennial ryegrass, host specificity, S148

-PMK1 MAP kinase pathway, genes, S127

-resistance breeding, S148

-on rice: molecular marker system for population study, S107; multispectral radiometer for assessment, 316; population biology, S148; resistance components, silicon effect, 63

-on ryegrass, mating behavior, S92

-on St. Augustine grass, silicon and chlorothalonil effect, S11

-on turf, challenges, S147

-on turfgrass, mating types in Georgia, S89; population genetics and management, S148

Maguire, T., S42, S113

Mahanty, S., S38, S55, S165

Mahdy, M., S138

Mahenthiralingam, E., S173

Mahovic, M., S6

Maier, D. E., S61

Maier, T., S134

Maize (see also Corn)

-late wilt, inoculation systems, S176

Maize chlorotic dwarf virus

- functional proteins, identification, S15

-resistance genetics, S178

Maize dwarf mosaic virus, movement in cultivars, S176

Maize streak virus

- kernel transmission by vascular puncture inoculation, S75

—virulence genetics, S25

Makselan, S. D., S121

Mallory, A., S162

Malvick, D. K., S57

Managbanag, J. R., S118

Management

—nematodes, site specific, S167

- plant health, ornamental plant principles, S172

Manandhar, G., S170

Manandhar, H. K., S170

Mandal, B., S57

Mandarin, postharvest green and blue molds, hot water and sodium carbonate effect, S69

Mandel, M. A., S36

Manfio, G. P., S58

Mangrove, fungi, distribution factors, S123

Manter, D. K., S186, S191

Manuscript preparation, author's guide, 7

Maragos, C. M., S17, S50, S115, S170

Marais, L. J., S58

Marasas, W. F. O., S124

Marchetti, M. A., 63

Marett, C., S167

Margolis, J., S158

Markell, S., S58, S179

Markham, P. G., S35

Marques, L. L. R., S58

Marra, M., S165

Mars, G. A., S179

Marshall, D., S16

Martin, D. L., S93

Martin, F. N., S58

Martin, R. R., S58

Martin, S. B., S203

Martin, T. J., S80

Martinez de Ilarduya, O., S136

Martínez-Espinoza, A. D., S165

Martinson, C. A., 477

Martyn, R. D., S26

Maruniak, J. E., S173

Marvelli, R. A., S58

Marys, E., S79

Mason, L. J., S61

Massart, S., S154 
Masunaka, A., S70

Mata, J. L., S118

Mata, M., S163

Matheron, M. E., S59, S186

Mathers, H. M., S59

Mathews, D., S183

Mathews, H., S58

Mathre, D. E., S153

Matten, S. R., S169

Matthews, P. S., 92

Matuszak, J. M., 882

Maupin, L. M., S59

Maurhofer, M., 873

Mavric, I., S71

Mavridis, A., S96

Mavrodi, D. V., 35, 44, S186

Mavrodi, O. V., 35, S186

Mavrodieva, V., S59

Maxwell, D., S45

May, K. J., S59

Mayberry, K. S., S48, S74, S84

Maymon, M., 586

Mayton, H., 1189, S4

Mazzola, M., 673, S33, S59

McBeath, J. H., S31, S59, S184, S187

McCabe, P. M., S47, S60, S90, S150

McCallum, H., S157

McCann, M. P., S165

McCarter, J. P., S159

McCartney, C. A., S60

McCaslin, M. A., S84

McClean, T. M., S119

McCleneghan, S. C., S103

McCollum, T. G., S84

McCormick, S. P., S170

McDaniel, D. P., S122

McDonald, B. A., 1011

McDonald, G. I., S155, S156

McDonald, M. R., S39, S43

McDowell, J. M., S159

McElreath, S., S83

McEvoy, J. L., S69, S73

McFadden-Smith, W., S60

McGavin, W. J., S45

McGawley, E. C., S138, S140

McGee, D. C., S20, S153

McGinnis, M. R., S170

McGonigle, T. P., S118

McGovern, R. J., S60

McGowen, J. L., S30

McGrath, J. M., S65

McGrath, M. T., S60, S196, S197

McHugh, J. V., S124

McKellar, M. E., S60

McKenry, M. V., S129

McKenzie, E. H. C., S104, S120

McKeown, S. P., S60

McLaughlin, D. J., S119, S126

McLean, K. S., S60, S69, S137, S138

McMahon, M. B., S61

McManus, P. S., S9, S61, S154

McMillan, R. T., Jr., S61

McMullen, M. P., S177

McNally, D. J., S196

McSorley, R., S145

McSpadden Gardener, B. B., 35, 44, S52, S61, S186, S187

Mecteau, M. R., S196

Medeiros, R. B., S26

Meier, A., S67

Meinhardt, S., S74

Mejia, J. F., S101

Meksem, K., S42, S113, S147, S169

Melakeberhan, H., S130, S132, S166

Melaleuca quinquenervia, fungal pathogens, in Florida, S75

Melamed, S., 741

Melampsora larici-populina, on poplar, resis- tance gene class, 1069

Melamspora $\times$ columbiana, on poplar, pathogenic variation, 981

Melcher, U., S8, S11

Melcion, D., S36

Meleo, P., S61

Meloidogyne spp.: biofumigation and soil heating for control, S141; diagnostic system, multiplex PCR, S203; on Lisianthus, host status and susceptibility, S141; nucleotide substitution pattern, S131; PCR identification and diagnostic system, S86; phylogenetic analysis, S133; on tomato, virulence marker and genetics, PCR diagnosis, 377; ToRuG, host response, S142

$-M$. arenaria, eggs colonized by Streptomyces spp., S135

-M. hapla, genetic variation, analysis, S138

-M. incognita: on Arabidopsis, Rhizobium etli colonization and biocontrol, 415; cell wall degrading enzyme, S21; on cowpea, isofemale lines, virulence, S140; gene identification on roots, S144; rectal gland cell observations, S140; staining procedure, red food stain, S144; on tomato, root penetration and egg production, S140

-M. javanica: adipokinetic hormone-like gene, S130; biocontrol with Trichoderma harzianum, 687; on cowpea, control with Steinernema and Xenorhabdus spp., S133; esophageal gland gene, S130; fungi for control, manure effect, S133; nematicides for, S133; ozone treatment in soil, $\mathrm{S} 141$

- M. konaensis, on coffee: irrigation and tree age effect, S143; magnesium partitioning, S136

-M. partityla, on pecan, New Mexico, S144

- M. trifoliophila, on clover, resistance molecular markers, S139

Melon (see also Cantaloupe and Watermelon)

- charcoal rot, drip irrigation in Arizona, S66

-vine-decline, management strategies, S84

Melton, T. A., S27, S35

Membreño, B., S199

Membreño, J. B., S199

Memmot, S., S164

Mendez, F., S61

Mendoza, L., S123

Meneses, R., S13

Meng, B., S71

Meng, X. Q., S179

Menge, J. A., 839, 847, S58, S98

Mennan, S., S138

Menzies, G. W., S182

Merabet, H., S12

Mercer, C. F., S139

Mercier, J., S61

Mermithids, insect parasitism, evolution, S172

Mertely, J. C., S54, S62

Mesocriconema xenoplax, on peach, rootstock evaluation, S140

Metarhizium anisopliae, on insects, catalyse activity, S104

Metcalf, A. E., S131

Metcalf, D. A., S17

Metchnikowia pulcherrima, apple blue mold controlled by, S43, 1098

Methven, A. S., S112

Meulia, T., S176

Mew, T. W., 282, S18

Meyer, F. W., S197

Meyer, R. J., 935

Meyer, S. L. F., S139

Meyer, T. R., S62

Meyer-Fernandes, J. R., 408

Meyers, D. M., S24

Miadlikowska, J., S118

Miao, Z. Q., S55

Micales, J. A., S102, S118
Michailides, T. J., 428, 665, 759, 864, 1197, S9, S16, S24, S56, S57, S103, S187

Michener, P. M., S62

Mickler, C. J., S62

Microdochium nivale

-Typhula spp. comparison, on turfgrass, fungicides for, $\mathrm{S} 87$

Microsphaeropsis spp.

—isolate comparisons, S193

- Rhizoctonia solani on potato controlled by, 782

Mihail, J. D., S62, S104, S156

Miklas, P. N., S186

Mila, A. L., S62

Miles, N., S60

Milgroom, M. G., S150

Miller, A. J., S143

Miller, A. M., S119

Miller, C. D., S63, S104

Miller, D. R., S64

Miller, G. L., S63

Miller, J. D., S71

Miller, J. S., S63

Miller, M. E., S19, S63, S199

Miller, O. K., Jr., S102, S126

Miller, S. A., S19, S99

Miller, S. L., S102, S112, S119

Miller, S. M., S63

Miller, T. C., S187

Miller, T. D., S63

Miller, W. G., 415

Millhouse, D. E., S202

Mills, D. (Oreg.), S63

Mills, D. A. (Calif.), S34

Millward, L., S121

Milus, E. A., S16

Minogue, T. D., S160, S196

Minsavage, G. V., S38

Minton, B., S18

Minz, D., 586

Mirabile, J., S63

Miranda, V. S., 599

Mirkov, T. E., S97, S161

Misaghi, I., 820

Mitchell, D. J., S86

Mitchell, F., S8, S11

Mitchell, J., S34

Mitchell-Fetch, J., S179

Mitchelson, K. R., 457

Mitkowski, N. A., S196

Miyata, S., 1024

Mizubuti, E. S. G., S64, S86, S119

Mizukubo, T., 377

Mizumoto, C. Y., S3

Mkandawire, A. B. C., S64

Mmbaga, M. T., S64, S201, S202

Mocz, G., S97

Model

- cultivar mixtures, pathogen evolution, intrapathotype diversity, 500

- epidemic dynamics and patterns, 1001

- mummy berry disease of blueberry, sequential sampling, 348

- Mycosphaerella graminicola, genetic recombination, 519

-Phomopsis leaf blight of strawberry, sequential sampling, 336

- virus diseases, epidemiology and cross protection, 924

-water transfer by rain splash in canopy, S78

-wheat and take-all, yield and loss, 694

Moens, M., S133

Mogen, K. L., S95

Mohamed, M. A., S129

Mohammadi, A. H., S5

Mohan, S. K., S64, S187, S188

Moleleki, N., S22

Molhoek, W. M. L., 485 
Molina, J. J., S97

Molina, R., S106, S109, S116

Momany, M., S117, S123, S126

Moncalvo, J.-M., S102

Mondal, S. N., S64

Money, N. P., S121

Monfort, W. S., S202

Monilinia spp., systemic fungicide resistance, detection in Australia, S95

-M. fructicola: on peach blossom, growth stage effect, S60; population structure in growing season, S9; on prune fruit, latent infection, factors, 864; on prune, latent infection and risk analysis, 1197; on prune, latent infection, S56; on prune, risk analysis, 759; on stone fruits and flowers, detection in California, S103; on stone fruits and flowers, species-specific detection, 428

-M. vaccinii-corymbosi: on blueberry, pseudosclerotial germination, 77; on blueberry, sequential sampling, 348; genetic variation, S180; North American collection, genetics and population diversity, S93; pseudosclerotial germination, tillage effect, $\mathrm{S} 65$

Monis, J., 274

Mononchida spp., in soil, species in Japan, S136

Monosporascus cannonballus

-on cantaloupe, fludioxonil for control, drip irrigation, S199

- on melon, vine decline, management strategy, $\mathrm{S} 48, \mathrm{~S} 74$

Montenegro, M., S55

Montenegro-Chamorro, M. V., S38

Moore, K., S139

Moore, M., S16

Moore, S. L., S81

Moorman, G. W., S31

Moos, J., S177

Moraes, M. G., S68

Morandi, M. A. B., S64, S119

Moreira, A. J. D., S167

Morello, J., S160

Moretti, A., S54

Morgan, D. P., 759, S57, S187

Morgan-Jones, G., S69, S138

Moricca, S., 457

Morin, C., S56

Morin, S., 188

Morphogenesis, saprolegniaceous fungi, surface gradient, 114

Morphospecies, concept in fungi, evaluation, S113

Morris, C. E., S89

Morris, K., S131, S173

Morris, T. J., S85

Morrison, R. H., S55

Morse, A. C., S64

Mortensen, W. S., S63

Moss, M., 558

Mount, J. R., S15

Mounter, S. A., S53

Moury, B., 84

Moyer, J. W., 891, S35

Moyseenko, J., S68

Mozafari, J., S87

Mudford, R., S37

Mueller, D. S., S10, S70, S175

Mueller, G. M., S110, S163

Mueller, J. D., S139

Mueller, J. P., S64

Mulawarman, J., S135

Mulberry, anthracnose, biological control, 181

Muller, J., S135

Mullin, P. G., S139, S143, S173

Mullinix, K., 673

Mullins, E. D., 173

Mullins, J. G. L., S151

Mulrooney, R. P., S21, S24
Mundo-Ocampo, M., S142

Mundt, C. C., 702, 993, 1011, S169

Mundt, C. M., S19

Muniyappa, V., S57

Munkacsi, A., S119

Munkvold, G. P., 477, 534, S20, S70, S95, S170

Muñoz, J. A., S69

Murphy, C. A., S140

Murphy, J. F., S30

Murphy, J. P., S37

Murray, T. D., 232, S24

Murrin, F., S163

Musa acuminata (see also Banana)

-microfungi, Thailand, S120

Mushroom

— cobweb disease, fungicide resistance, $\mathrm{S} 8$

- green mold, calcium oxalate effect, S3

-identification, digital imaging, S110

-media, spent grain recycling, S111

Musser, R. O., S65

Mutagenesis, genome scale, analysis in fungi, S165

Muths, E., S108

Mwangi, F. M., S37

Myburg, H., S125

Mycena spp., taxonomy, in California, S120

Mycology, field and lab, matter and antimatter, S122

Mycorrhizae

-arbuscular, species composition in Arizona, S107

— genes coded for protein, symbiosis, S86

—on oak seedlings, plant links, S117

Mycosphaerella spp.: anamorph concepts redefined, S107; on corn, phylogenetic analysis, 648

-M. citri, on citrus, fenbuconazole for, S64

-M. fijiensis, on banana, detached leaf assay, S61

-M. graminicola: ascospore number initiating epidemics, estimation methods, 1011; gene disruptions, S38; genetic recombination and epidemic, pseudothecia effect, 240; genetic recombination model, 519; transposable element, S88; on wheat, active transposable element, DNA fingerprinting probe, 1181; on wheat, genome-scale gene identification, function analysis, S55; on wheat, reproduction and resistance, $\mathrm{S} 19$

$-M$. pinodes, pathogenicity and genetic analysis, S99

Mycotoxin

-aflatoxin: on corn, silk antibiotic compounds, S34; food contamination and health, in West Africa, S171; in leguminous trees, in Arizona, 913; nitrate inhibition, NADPH, S73; resistance sources in corn, S89

-apicidin and HC-toxin, effect on duckweed, 1141

-Bipolaris sorokiniana, on barley, Mlo pathway, 127

- fumonisin, FDA guidelines for corn, S170

-Fusarium spp., Nepalese food grain, S170

-management in United States, costs, S170

Mycovirus

-horizontal transmission, S150

- symptom induction, S150

Myrothecium roridum, on melon, resistance screen, S19

Myxomycetes, in New Zealand, alpine snowbank, S124

Myzus persicae, virus of and effect on virus transmission, S87

Nadeem, A., S35

Naeve, S., S178

Nagarajan, S., 127

Nagata, N., S90
Nagata, R. T., S11

Nagendran, S., S65

Naidu, R., S4

Nakabonge, G., S77

Nakaho, K., S95

Namba, S., 1024

Nanayakkara, R., S65

Nanobiotechnology, cell biology applications, S163

Narabu, T., 377

Narisawa, K., S187

Natvig, D. O., S114

Natwick, E. T., S90

Navas-Cortés, J. A., 807

Neate, S. M., S195

Nectria haematococca

- extracellular fungal matrix, adhesion, S149

-on pea, recombinants and virulent isolates, 92

Neher, D. A., S139

Neilson, R., S39, S65

Nekouei, F., S119

Nelson, B. D., S65, S179

Nelson, E. B., S46, S60, S72, S83

Nelson, G., S38, S55

Nelson, M. E., S9, S71

Nelson, M. R., 1156, S181

Nelson, R. (S. Africa), S187

Nelson, R. J. (N.Y.), 956, 993

Nelson, R. L. (Ill.), S16

Nelson, R. S. (Okla.), 440, S162

Nematicides

- Bt toxins, S145

-integrated management, S174

-root-knot nematode, on tomato, doses, S136

Nematodes

-all-taxa biodiversity inventory, Great Smoky Mountains National Park, S131

—applied genomics, industry perspective, S174

—chemical management, Louisiana, S138

- cell cycle gene, functional analysis, S141

- community structure: analysis, S131; plant amendment effect, S146

-control with health promoting agent, TerraPy, S135

- Cry6A toxin, control method, S135

—entomopathogenic: aphid predator antagonistic to, S141; strategies, S173; survey in Great Smoky Mountains National Park, S130; temperature and trehalose accumulation, S136; tritrophic interactions, S137

-esophageal gland cells, parasitism, S161

- extraction with Baermann funnel, S140

- fungi on, biodiversity in Hong Kong, S125

-fungi trapped by, parasitism evolution, S173

-high throughput gene discovery, S159

-Hirsutella rhossiliensis parasitic to, soil $\mathrm{pH}$ effect, 324

—human parasites, genome projects, S174

-in orchards, suppression by endophyte-infected fescue, $\mathrm{S} 135$

-insect parasitism, evolution trends, S172

—insect transmitted, parasitism evolution, S173

-in wetland soils, North Carolina, S139

- juvenile response to host cuticle, S131

-management, cropping systems, S145

-molecular diagnostics: S143; cropping system soil, S152

—mollusk parasitism, evolution, S173

-on turfgrass, distribution in putting greens, S83

-parasitism evolution, overview, S172

-plant interaction, endoglucanase expression, S134

- plant-parasitic, survey in gold courses near Gulf of Mexico, S132

—plant parasitism, evolution, S173

- profile in soil ecosystem, S134

-reproduction in tall fescue, endophyte relations, S144 
—rhabditid and diplogastrid, insect parasitism evolution, S172

-root-knot, esophageal gland genes analysis, S137

—-secretions, plant parasite role, S161

- soil, molecular barcodes for identification, S134

-taxonomy: database management system, S146; in Egypt, S129

Neotyphodium coenophialum, ergot alkaloid synthesis by, gene, $\mathrm{S} 123$

Nesbitt, M., S60

Nesmith, W. C., 1224, S38

Nesson, M., S189

Neurospora spp., model system, 114

$-N$. crassa, hyphae, cytoplasmic organization and intracellular motility, S122

Newcombe, G., 981, 1081

Newton, M. R., S158

Neyrinck, S., 1069

Ngugi, H. K., 720, S65

Ni, H. F., S66

Niblack, T. L., S43, S130, S132, S139

Niblett, C. L., S67

Niblett, C. N., S67

Nicholson, R. L., S148, S149

Nicotiana spp. (see also Tobacco): downy mildew, host-pathogen interaction, 1224; Potato leafroll virus, mutant movements, S54

$-N$. benthamiana, multiple virus resistance, short synthetic gene, $\mathbf{S} 28$

$-N$. bigelovii, Cauliflower mosaic virus, gene for hypersensitivity, S14

$-N$. repanda, downy mildew, resting structures, S38

Nie, X., 197

Nielsen, C. J., S188

Nielsen, K., 527, S120

Nirenberg, H. I., 1231

Nischwitz, C., S66, S188

Nishigawa, H., 1024

Nishimura, K., 1166

Nita, M., S66

Nitao, J. K., S139

Niwa, C., S155

Njiti, V., S42, S113

Noel, G. R., S129, S130, S139, S176

Noguchi, K., 1166

Nolin, S. J., S45

Nolte, P., S188

Nordheim, E. V., S108

Norelli, J. L., S66

Norman, D. J., S66, S200

Norris, L. P., S135

Northover, J., S60

Norton, J. A., S66

Norton, M. A., S16

Notz, R., 873

Nunez, J., S183

Nuss, D. L., 628, S150

Nutter, F. W., Jr., 659, S7, S53, S166, S167, S177, S179

Nyczepir, A. P., S140

Oak (see also Quercus alba)

— sudden death, Phytophthora canker, California, S76

—wilt, epidemiology and remote sensing, S13

Oakley, B. R., S162

Obermeier, C., 797, S150

Obituaries

-Robert M. Hanau, 616

-Merritt Richard Nelson, 820

O'Brien, S., S98

Ocamb, C. M., S9

Ochoa, F. M., S67

Ockey, S. C., S67, S88

O'Connell, N. V., S58
O'Connell, R. J., 149

Odell, T. E., S106, S109

O’Donnell, K., 1037, 1231, S151

Odontoglossum ringspot virus, on Nicotiana

sylvestris, characterization of component, S74

Oerke, E.-C., S67, S85

Oetting, R., S12

Ogata, D., S90

O'Gorman, D., S81

Ohnishi, J., 1149

Ohr, H. D., S84

Okada, H., S140

Okie, W. R., S140

Olatinwo, R. O., S67

Olaya, G., S33, S67

Olive

—drying syndrome, status in Argentina, S71

-knot, pathogen identification by PCR, S6

Olive, J. W., S35

Oliveira, A. M. R., S68

Olmstead, J. W., S188

Olsen, M. W., S66, S188

Olsen, N. L., S63, S188

Olson, M. E., S58

Olzem, B., S37

Omarov, R. T., S27, S68

Omer, M., S68

Omphalina spp., nucleotide substitution rate, algal comparison, $\mathrm{S} 128$

O'Neill, N. R., S5, S89, S104

Onesto, J.-P., 84

Ong, K. L., S202

Onion

-Botrytis allii, epidemiology, S17

- Botrytis spp., subgroup distinction, method, 527

— center rot, seed infection, S92

- foliar disease, fungicide, $\mathrm{S} 18$

—-smut, management with Allium products, S39

-yellows phytoplasma, stunting and hyper-

plasia, derivative lines, 1024

Ooka, J. J., S68

Ophiosphaerella agrostis

-on turfgrass, fungicides, S197

Ophiostoma spp., sapstain and biocontrol agents, biomonitoring protein, $\mathrm{S} 186$

-O. floccosum: HN reductase, DHN melanin gene coding, S93; melanin synthesis, DHN pathway, S191; THN reductase gene, cloning, S185

-O. piceae, on conifers, genetic variability, 369

$-O$. piliferum: albino mutant of, biocontrol agent, S49; genetic variability in Canada, S8; sapstaining species, marker differentiation, S185

Opperman, C., S97, S139, S147

Orbach, M. J., S36

Orban, S., S87

Orchid, fungal endophytes, zymogram analysis in Australia, S2

Orf, J. H., S137, S139

Orion, D., S140

Orlicz-Luthardt, A., S108

Ornamentals

—bacterial pathogens, in Puerto Rico, S200

-disease in Utah, S172

Orobanche spp., pathogens of, in Jordan, S35

-O. crenata, faba bean resistance, $\mathrm{S} 111$

-O. cumana, Fusarium oxysporum as mycoherbicide, $\mathrm{S} 81$

Orum, T. V., 1156, S181

Osborne, L., S44, S68

Oscheius spp., on Formosan termite, molecular phylogeny, S131

Oshima, K., 1024

Osman, Z., S18

Osmundson, T., S107, S120

Østergård, H., 240

Ostrofsky, A., S44
Ostry, M., 1081

Otero, L., S71

Otrosina, W. J., S93, S204

Oudemans, P. V., S93, S167, S180

Overmars, H., S21

Overstreet, C., S68, S138, S140

Overton, S., S197

Owen, J. D., S157

Owen-Going, T. N., S68

Ownley, B. H., S81, S202, S203

Ozturk, S. B., S6

Pace, P. F., S94

Padgett, G. B., S68

Paecilomyces tenuipes, programmed cell death induction, S115

Pagani, C. M., S68

Pair, S., S8, S11

Palacios, N., S3

Palanichelvam, K., S69

Palm, M. E., S151

Palmateer, A. J., S69, S138

Palou, L., S69

Palukaitis, P., S54

Pan, S. Q., S44

Pan, Y. B., S33

Panella, L., S36, S45

Panicum mosaic virus, replicase proteins, S7

Panis, B., S38

Pannu, S. S., S74

Panter, K. L., S27

Pantoea stewartii, polysaccharide synthesis, quorum sensing, S160

Panwar, M. S., 255

Papaver somniferum, xanthomonad pathogenic to, in field, S79

Papaya, Asperisporium caricae on, in Hawaii, S90

Papaya ringspot virus, resistance cultivars, Hawaii, S168

Papert, A., S134

Pappu, H. R., S57, S94, S202

Paratrichodorus spp., Trichodorus compared to, molecular phylogeny, S10

$-P$. anemones: lectins and specific attachments, S39; virus vector, feeding behavior, S46

Parda, K. W., S69, S95

Parisi, L., 900

Park, D. H., S4

Park, E. (Md.), S69

Park, E. W. (Korea), 165, S49

Park, G., S29, S120

Park, J.-W., S27, S162

Park, K. H., S80

Park, S.-W., S69

Parke, J. L., 383, S63

Parker, R. C., S27

Parra, A. L., S7

Parra, G. P., S59

Parra, J. R. P., S7

Parsons, C. E., S23, S70

Partridge, D. P., S70

Pasteuria spp., on nematodes, systematics phylogeny, S173

Pastor-Corrales, M., S70

Pataky, J. K., 293, S50, S62, S115

Pathirana, S., S45, S159

Pathogenicity, genome-wide analysis, S159

Patil, S. S., S97

Paul, P. A., S70

Paul, R. N., 1141

Paulitz, T. C., S21, S70, S89

Paull, R. E., S47

Paveley, N. D., 708

Payne, G. A., S73

Pea

- Nectria haematococca, virulent recombinants in isolates, 92 
-oomycete pathogens, biocontrol with Burkholderia cepacia, 383

-root rot, defense mechanisms, cytology, 730

Peach

-bacterial spot, fruit infection periods, S68

-constriction canker, inoculum availability, 1109

-rusty spot: epidemic and management, S194; epidemic analysis, S195

- scab, fungicide spray program, S82

— scab and plum curculio, spray strategy, S52

Peanut

-Aspergillus and aflatoxin, fungicide effect, S11

- early leaf spot, fungicide regimes and timing, S202

—early spot, fungicides, S201

- foliar and soilborne diseases, fungicide control, S13

—fungicides, broad spectrum, S202

- leaf spot and rust, spray program, S50

-nematode, resistance locus, S17

— pod and root rot, paclobutrazol effect, S181

_ pod rot, calcium effect, S201

-root-knot nematodes, germ plasm resistance, $\mathrm{S} 130$

- southern stem rot, disease assessment methods, S203

-Tomato spotted wilt virus: planting date effect, S60; response and movement, S57

Peanut chlorotic fan-spot virus, molecular characterization, 856

Pear

- fire blight, biocontrol enhancement with iron chelate, S86

-fruit russeting, involvement of Aureobasidium and Rhodotorula, $\mathrm{S} 83$

Pearl millet, rotting stalks, fungal distributions, S204

Pearlsman, M., 565

Pearson, M. N., S168

Pecan

— powdery mildew, nut quality effect, S188

—scab, yield loss, S85

Pecota, K. V., S12

Pectin, in plants, bacterial lipopolysaccharide interaction, S91

Pedersen, W. L., S10, S12, S39, S70, S175

Pederson, J., S177

Peever, T. L., S70, S109, S188, S190, S192

Pelosi, R. R., S72

Peng, Y.-C., 856

Penheiter, A. R., 204

Penicilliopsis pseudocordyceps, new trichocomaceous fungus, $\mathrm{S} 112$

Penicillium spp.: on apple, conidia in packinghouse air, S197; on citrus peel, components, S84

- $P$. expansum, on apple, invasion during storage, S197

Pennings, G. G. H., 134

Pennisetum glaucum, resistant gene management, multiline approach, 255

Pennycook, S., 633

Peoples, K., S38, S55

Pepper (see also Capsicum spp. and Piper methysticum)

-Fusarium solani and Erwinia carotovora on, $\mathrm{K} / \mathrm{N}$ and $\mathrm{pH}, \mathrm{S} 182$

-Phytophthora capsici, genetic structure, 973

Percich, J. A., S27, S177

Percifield, R. J., S179

Pereira, R. M., S81, S130

Peres, N. A. R., S71

Perez, B. A., S71

Perez, E. E., S131, S140

Perez, W. G., 956

Peridermium pini, Cladosporium tenuissimum antagonistic to, 457
Periwinkle, western aster yellows phytoplasma, gene detection, S186

Peronospora spp.

- . parasitica, on crucifers, microsatellite isolation, S185

-P. tabacina: on Nicotiana spp., host-pathogen interactions, 1224; on tobacco, seed germination effect, S38

Perrott, R., S14

Perry, B. A., S120

Perry, K. L., S29

Perry, R. N., S143

Pesic-Vanesbroeck, Z., S12

Pest management

- citrus bacterial canker and citrus leaf minor, interaction, S7

— crop profiles, database on World Wide Web, S89

Pestalotia malicola, conidial morphology and extracellular matrix, S149

Pestalotiopsis spp., phylogenetic relation, DNA sequence, 114

Pesticide

—organic, Neem tree product based, S142

-resistance management, EPA and regulations, S169

Pesticide technology, airblast and Proptec rotary atomizer, comparison, S75

Petersen, R. H., S110, S116, S118

Peterson, A. B. R., S71

Peterson, D. A., S187

Peterson, G. L., S71

Peterson, K. R., S120

Peterson, P. D., S71

Pethybridge, S. J., S37, S71

Petracek, P. D., S30

Petrillo, M. D., S140

Petrovic, N., S71

Pettersen, M. S., S71

Pfender, W. F., 111, S72

Pfister, D. H., S128

Phaeoacremonium spp., on grape, in California, $\mathrm{S} 185$

-P. chlamydosporum, on grape, pycnidial production, S191

Phaeocryptopus gaeumannii, on Douglas fir: disease, development, S186; needle infection, S191

Phaeoisariopsis griseola, on bean, yield loss, 1045

Phaeosphaeria nodorum, segregation and sexuality, S20

Phaseolus vulgaris

- angular leaf spot and rust, yield loss, 1045

- microbial interaction in soil, PCR use, S28

-resistance to Xanthomonas campestris, genotype identification, S199

-rust and anthracnose, photosynthetic competence, 212

-rust and mosaic resistance, germ plasm lines and multiple genes, S70

- white mold, calcium sulfate effect, S177

Phasmarhabditis hermaphrodita, bacteria and slug relation, virulence mechanism, S144

Phenacoccus aceris, little cherry disease vector, characterization, 268

Phialophora gregata, on soybean

- colonization indicator, S180; cyst nematode relation, S180; microsatellite markers, S176; multiple infections, S176; preferential infection of cultivars, S179; resistance alleles, S16

Philion, V., S72, S197

Phillips, A. N., S120

Phillips, M. S., S10

Phoma spp.

- P. medicaginis, molecular variability, S13

-P. sclerotioides: on alfalfa: detection with PCR-based SCAR markers, S53; PCR markers,
S186

Phomopsis spp.: on cucurbits, phylogenetic distinction, S105; on grape and blueberry, disease patchiness measurement, S77

- P. amygdali, on peach: inoculum availability, 1109; modeling sporulation, S51

-P. obscurans, on strawberry: infection factors, S66; sequential sampling for incidence, 336

- $P$. viticola, on grape: molecular characterization, S48; rachis and berry infection, S27; spore release patterns, S77

Photita, W., S120

Phyllosphere, resource aggregation, spatial scales, S158

Phylogeny, fungal relations, relevance, S164

Phytoalexin, Colletotrichum sublineolum on sorghum, host defense response, 149

Phytolacca americana, protein from root exudate, antifungal, S69

Phytomedicine, medicinal plants and spices, German society, S108

Phytomonas françai, plant parasites, phosphatase activity, 408

Phytophthora spp.: on cucurbit and solanaceous crops, relative susceptibility, S39; developmental progression, phage-display peptides, S53; in irrigation water, Wenatchee River Valley, S192; mitochondrial gene sequences, molecular phylogeny, S58; on oak, sudden death, control, S30; P. glovera and P. bisheria compared, molecular characterization, S1; sudden oak death association, California, S108; sudden oak death, genetics, California, S110; survival in irrigation runoff, ornamental nurseries, $\mathrm{S} 92$

$-P$. bisheria, on strawberry, characterization, $\mathrm{S} 1$

-P. capsici: on chili pepper, Actigard and Ridomil Gold effect, S186; on cucurbits, genetic structure in Michigan, 973; disease management, spatiotemporal genetic structure, in Michigan, S166; mefenoxam insensitivity, AFLP markers, S195; mefenoxam insensitivity, dynamics and method, 553; prevalence factors, in Florida, S72; on pumpkin, seed treatment, $\mathrm{S} 4$; on pumpkin and tomato, seedling death management, red light, S43

-P. cinnamomi: biocontrol, eucalyptus mulches, enzymes, 847; cellulytic enzymes, effects, 839; mycelium, cellulase effect, cover photo, September; on loblolly pine, decline site in Alabama, S93; $P$. nicotianae comparison, mefenoxam sensitivity, S24; potassium phosphite effect, S50; on woody perennial, control factors, S59

-P. fragariae, on strawberry, in California, S91

-P. infestans: fungicide resistance, in Mexico, $\mathrm{S} 33$; in 19th century herbarium specimens, identification, S59; isolate characterization, FAME profiles, S53; oospore formation, Mexico, S28; population specificity, epidemiology in Brazil, S86; population structure, Central Mexico, 882; population structure, in Nepal, S31; population virulences, persistence in Washington, 606; populations in Peru, genetics, 956; on potato and tomato, in Maine, $\mathrm{S} 33$; on potato tuber, oospore formation, 579; on potato, cold tolerance, S81; on potato, epidemiology in tropics, 993; on potato, field resistance and aspartic proteinase, S34; on potato, sporangial escape in canopy, $\mathrm{S} 4$; on potato, tuber storage, S188; on tomato and potato, genotype analysis, geostatistics, in Mexico, 1156; on tomato and potato, international trade effect, S153; on tomato fruits and seeds, oospore production, 1074; Solanum spp. susceptible to, S183; sporangial release and escape, quantifying, 1189; in Washington, characterization, S42 
-P. parasitica: on citrus, fungicides toxic to, S62; on citrus, Pseudomonas fluorescens for control, cytochrome $c$ maturation gene, S76; suppressive medium with aluminum-peat complex, 1092

- P. phaseoli: on baby lima bean, fungicide evaluation, S24; on Delmarva, isolate characterization, S21; mefanoxam sensitivity, S24

-P. polygoni, on Rumex dentatus, in China, S99

$-P$. sojae, races in Minnesota soils, changes, S51

Phytoplasma

-aster yellows: chromosomal fragment, sequence analysis, S74; cloned fragment of strain, S189; DNA-binding protein gene in plasmid, S76; genomic DNA from lettuce, S99

- aster yellows and clover proliferation groups, differentiation, 546

-beet leafhopper-transmitted virescence agent, detection, S183

- characterization in Wisconsin, S179

- conserved and semiconserved gene sequences, PCR primers, $\mathrm{S} 152$

- detection by polymerase chain reaction, vector ability, 741

-loofah witches' broom, rRNA interoperon sequence heterogeneity, S21

- on onion, stunting and hyperplasia effect, 1024

Picea mariana, needle rust, plant competition and telial density, S62

Piche, Y., S124

Pichia spp.

- P. guilermondii, biocontrol agent, for Botrytis on strawberry, 621

- P. pastoris, cellulases from, soybean cyst nematode, $\mathrm{S} 24$

Pierce, F. J., S130

Pierson, L. S., III, S160, S182

Pietri, A., S36

Pigeonpea sterility mosaic virus, mite vector, characterization, S51

Pilcher, C., S17, S36

Pilgeram, A. L., S79, S100

Pilon, M., S157

Pilon-Smits, E. A. H., S157

Pilowsky, M., 1209

Pimentel, G., 935

Pine

-late wilt, disease source, S184

-loblolly and longleaf, starch and root cells of, S93

- ponderosa, ecosystem components and prescribed fires, Blue Mountains, S155

Pineapple, reniform nematode reproduction, protease inhibitor, S47

Pinkerton, J. N., 1214

Pinus spp., ectomycorrhizae, revegetation of stressed site in Virginia, S102

- P. banksiana: needle rust, plant competition and telial density, S62; Scleroderris canker, ligno-suberized tissue formation, 1128

$-P$. radiata,pitch canker, twig beetle as vector, S78

-P. strobus, fungal endophytes, biodiversity, S124

Pio-Ribeiro, G., S202

Piotrowski, J. S., S121

Piper methysticum (see also Pepper)

— shot hole disease, in Hawaii, S68

Pistachio

-Botryosphaeria blight, biocontrol agents, S16

-Botryosphaeria dothidea, resistance to tebuconazole, S57

- split nuts, rootstock effect, S24

Pistacia vera, Botryosphaeria panicle and shoot blight, population in California, 665

Pitts, J. A., S82

Piva, G., S36
Plaisance, K. L., 1141

Plant defense, response and signaling pathway, genetics, S159

Plant doctor, definition, S171

Plantago asiatica mosaic virus, Nandina mosaic virus relation, $\mathrm{S} 41$

Plasmopara viticola, on grape: biocontrol with Fusarium, 1062; ontogenic resistance, S47

Platt, J. L., S121

Plattner, R. D., S170

Platzer, E. G., S141, S172

Ploeg, A. T., S141

Ploetz, R. C., S72

Plovie, E., S141

Plum pox virus

- Canadian isolates, molecular characterization, S43

—isolates in Pennsylvania, sequences, S59

-multiple isolates per tree, sequence analysis, S36

-Pennsylvania isolate, host range, S20

-on Prunus spp., determinant identification, 159

—-spatial pattern analysis, Pennsylvania, S32

Plummer, K. M., 633

Podila, G. K., S10, S86

Podleckis, E. V., S153

Podocarpus, pink disease, in South Africa, S78

Podosphaera spp.

- $P$. clandestina, on sweet cherry, digital image analysis, $\mathrm{S} 188$

- P. fusca, on cucumber, strobilurin resistance, 1166

Poinar, G. O., Jr., S172

Poinsettia

-Rhizoctonia crown and root rot, potting mix effect, 1116

-Rhizoctonia stem rot, resistance, S41

Poinsettia mosaic virus, Venezuelan isolates, molecular characterization, S79

Polashock, J. J., S195

Polek, M., S81

Polgrabia, J., S60

Polyporus spp.

-biological species, phylogeny, S116

Pomella, A., S79

Ponce, F., S72

Pond, E., 839, 847, S98

Poplar, hybrid, rust, pathogenic variation, 981

Populus deltoides

—rust, resistant gene class, 1069

- Septoria canker, resistance inheritance, 1081

Porchas, M., S59, S186

Porter, L. D., S72, S188

Portillo, H. E., S202

Portulaca oleracea, herbicide effect, S2

Postharvest pathology

-biocontrol agents, Pichia and Pantoea, S85

-biocontrol: microbial habitats on plants, S154; postharvest fruit diseases, S154

-fruit, bioactive coating, S155

-fruit decay: new fungicides, S84; polyols and sugar effect, S155

- pome fruits, biocontrol agents, S155

- stored grain, ozone fumigation, S61

Postnikova, E., S79

Potato

-blackleg, genetic variability of pathogens, S68

-cropping systems, soil microbial communities, attributes, S53

-cyst nematode: electrical activity analysis, S143; genetic structure and agricultural practice, 753; parasitism genes, S174

-Fusarium dry rot, salts, S196

-late blight: epidemiology in tropics, 993; fungicides, resistance, S50; fungicides, spore sampling, S197; Idaho, S188; Peruvian populations, genetics, 956; population structure in Central Mexico, 882; resistance in advanced lines, S72; resistance mechanisms, S71; solanaceous hosts in Pacific Northwest, S184; sporangial escape from canopy, 1189

-mancozeb chemigation on, disease control, S63

—nematodes and viruses, R-gene homologues, S147

- Phytophthora infestans, virulence complex in Washington, 606

—pink rot, biocontrol with Trichoderma, S59

- postharvest disease, bacteria for biocontrol, S83

-Rhizoctonia solani, AG-3, gene flow, S105

- soilborne diseases, metam sodium effect, S136

- tuber infection, oospore formation by Phytophthora, 579

- tuber soft rot, postharvest application of salts, S198

—Verticillium dahliae and Pratylenchus penetrans, combined inoculation response, S68

Potato virus A, differential accumulation, hypersensitivity, 197

Potato virus $X$

—chalcones, antiviral activity, S29

-resistance genes, Globodera pallida relation, S143

Potato virus $Y$

- suppression and silencing by Red clover necrotic mosaic virus, $\mathrm{S} 83$

- virus titer in cultivars, S177

Poupet, A., 84

Powell, A. J., S114

Powell, C. A., S72

Powell, J. F., S8, S72

Powell, J. R., S141

Powell, M. J., S105, S116, S121

Powellomyces spp., species delineation, S121

Powelson, M., S184

Powers, K., S175, S199

Powers, T. O., S139, S143, S173

Prabhu, A., S77

Pratt, P. D., S75

Pratt, R. G., S73

Pratylenchus spp., molecular and morphological characters, S131

$-P$. penetrans: on lily, hot water and ozone treatments, S134; on pearl millet, sorghum, potato, yield effect in Quebec, S130

-P. vulnus, Criconemella xenoplax population compared to, in California walnuts, S145

Preisig, O., 628, S22

Press, C. M., 593

Preston, A. K., S63

Preston, J. F., S173

Price, J., S68

Price, M. S., S73

Price, W. O., S137, S141

Pringle, C. M., S123

Prins, P., S174

Priyatmojo, A., 1054

Probert, S. L., S81, S181

Prodi, A., S90

Prosopis spp., biocontrol in South Africa, S54

Proteaceae, saprobic fungi, biodiversity in South Africa, S116

Protein cysteine residues, SDS gel method, S52

Prune

-brown rot: latent infection and risk analysis, in California, 1197; latent infection factors, 864

—brown rot blossom blight, risk analysis, 759

Prunus necrotic ringspot virus

—phylogenetic analysis, S36

-on rose and Prunus spp., survey, 84

Prunus spp., replant disorder, fungi associated, S12

Prusky, D., 143, S69, S73

Pryce Miller, J. E., S121

Pryor, A., S134, S141 
Pseudomonas spp.: antibiotic DAPG produced by, crop preferences, S52; genetic diversity oleic acid conversion, S124; genetic diversity of phlD 35, 228; rhizosphere population, population density, 44

-P. aureofaciens, phenazine biosynthesis, S182

- P. chlororaphis: biocontrol agent, transport protein encoding, S48; root colonization by, kinase GacS, S49

-P. fluorescens: antibiotic deficient mutant, S87; biocontrol agent for take-all, genetic diversity, $\mathrm{S} 186$; biocontrol in rhizosphere, biotic factors, 873; biosurfactant in vegetable decay, S38; on wheat, rhizosphere changes, $\mathrm{S} 23$

- P. savastanoi, on olive: characterization in Turkey, S6; detection by membrane bio-PCR, S6

- P. syringae: in almond, bud drop symptom, S79; biocontrol agent, postharvest fruit diseases, S7; on cherry, management strategy in New York, S37; coronatine effect on virulence, S159; on Cynoglossum officinale, valine and virulence, S100; on fenugreek, new in New Jersey, S194; on fenugreek, seed infection, S28; pathovar virulence, ethylene role, 511; protein secretion system, type III, $\mathrm{S} 160$; on rappini crops, persistence in replant crop, S17; tabtoxin pathogenicity island, DNA sequence, S49; transcription factor, gene encoding, thermoregulation, S97; ultraviolet sensitivity, encoded gene effect, S63

Pseudoperonospora cubensis, on cucumber, strobilurin resistance, 1166

Pseudozyma flocculosa

— biocontrol agent for powdery mildew, S193

- powdery mildew: antagonist, molecular analysis, 249; biocontrol agent, genetic transformation, S194

Pterula, Deflexula relation, evolution, S119

Puccinia sp., biocontrol of dyer's woad, GPS/GIS technology, S191

- P. dioicae, on goldenrod, rainfall effect, S22

-P. glechomatis, on ground ivy, spread, S104

$-P$. graminis, history of Berberis quarantine, S115

-P. lagenophorae, biocontrol agent for Senecio madagascariensis, in Hawaii, S48

- P. menthae, on peppermint, biofungicide, S82

$-P$. recondita, on grasses and cereals, phylogeny, S1

-P. sorghi, on sweet corn, trait loci, 293

$-P$. striiformis: on wheat, epidemics in the United States, S16; on wheat, heritability and transgressive segregation, 680

- P. substriata, on pearl millet, resistance gene management, 255

- P. triticina, on wheat, physiological specialization in Nebraska, S123

Puckhaber, L. S., S40, S95

Puehringer, H., S36

Pullen, M., S29

Pumpkinm Phytophthora blight and fruit rot, fungicides, S42

Punja, Z. K., S73, S183

Pusey, P. L., 77, S73

Putnam, M. L., S189

Pyrenopeziza brassicae, on oilseed rape debris, survival, factors, 392

Pyrenophora tritici-repentis

-host-selective toxin, RGD motif, S74

-race 2, S29

- on wheat, RFLP map, resistance to races, 572

Pyricularia grisea

-fungicides, molecular basis of resistance, S110

-on ryegrass: biocontrol with bacterium, S92; fungicide resistance, S92; resistance, S35

-on ryegrass turf: epidemics, S198; nitrogen effect, S90

Pythium spp.: AFLP for characterization, S31; on bermuda grass, overseeding in Florida, S86; on pepper, root symptoms in hydroponic crops, S68

- $P$. aphanidermatum: developmental stage, pyraclostrobin, S46; on pea, biocontrol with bacteria, 383

- P. insidiosum: human mycoses, tissue invasion, S121; intraspecific variation, ITS sequence analysis, S123

Qi, M., S73, S98

Qi, W., S73

Qin, X., 599

Qiu, D., S74

Qiu, J. J., S141

Qiu, W. P., S74, S162

Qu, L.-H., S106

Quadt-Hallmann, A., 415

Quarantine, rusts and U.S. ports of entry

Quercus alba (see also Oak)

-fungus eradication, temperature effect, S25

Quinn, J. A., S63

Quiot, J.-B., 159

Quiot-douine, L., 159

Rabindran, S., S74

Racine, G., S8

Rademacher, M. R., S74

Radewald, K. C., S74, S84

Radish, Rhizoctonia damping-off, potting mix effect, 1116

Ragazzi, A., 457

Ragsdale, A. F., S121

Rahman, M., 702

Rai, K. N., S169

Raid, R. N., S171

Raina, R., 173

Raja, H. A., S121

Rakes, L., S142

Ralstonia solanacearum

— diversity in southeastern United States, S202

-Japanese strains, genetic diversity, 399

Ramadan, M., S48

Randhawa, P. S., S74

Rane, K., S26

Rangel, Y., S121

Ranjekar, P. K., S6

Rape (see also Canola)

-leaf spot, apothecia survival on debris, 392

Rascoe, J., S74

Rascual, C. B., 1054

Rashid, K. Y., S188

Rasmussen, J. B., S29, S30, S74

Rasmussen, S., S66, S188

Raspberry, spur blight, S182

Raspberry bushy dwarf virus, in red raspberry, resistance, $\mathrm{S} 58$

Ravishankar, J. P., S121

Ravnikar, M., S71

Rawnsley, B., S48

Rayachhetry, M. B., S75

Raymundo, R. M., 956

Re, E. B., S11

Rea, C., S75

Reade, R., S87, S150

Red clover necrotic mosaic virus

_-gene silencing, resistance, S94

- movement proteins, identification, S89

Red clover vein mosaic virus, on chickpea, yield, S186

Reddick, B. B., S75

Reddy, D. V. R., S51

Reddy, M. S. S., 831

Redhead, S. A., S122

Redinbaugh, M. G., S15, S75, S176, S178

Redman, R. S., S39

Redmond, C. T., 831

Reed, J. T., S141
Reedy, R. A., S28

Reedy, R. M., S8, S75

Reeser, P. W., S189

Regalado, E., 282

Regulation, standards and risk, trade issues, public health, S170

Reich, L., S66

Reich, P. B., S126

Reich, R. M., S156

Reid, D. M., S58

Reil, W. O., S145

Reilly, C. C., S75

Reis, L. G. L., S142

Reissinger, A., S75

Rekah, Y., S76

Renard, M., 70

Resendiz, R., S66

Resistance

-antibiotics: fire blight, S154; postharvest horticultural crops, S154

-boom and bust cycle, strategies, S169

-microbial: postharvest horticultural crops, S154; public health action plan, S154

_ pearl millet, strategies, S169

_ pearl millet to rust, multiline approach, 255

- poplar to Septoria stem canker, recessive, 1081

-rice to blast, silicon effect, 63

- systemic acquired: calcium effect, S86; regulation by NPR1, S159

-wheat: to Barley yellow dwarf virus, 55; to Cephalosporium stripe, toxin sensitivity, 702; to stripe and yellow rust, 680

Reuter, M. E., S171

Reviewers, acknowledgment for 2000, 4

Reyes, L., S13

Rezende, J. A. M., S68

Rhizobacteria, microbial gene expression patterns, S160

Rhizobium etli

-Arabidopsis root colonization, biocontrol for nematodes, 415

-on Arabidopsis roots, nematode-infected, cover photo, April

-on nematodes, biocontrol, S138

Rhizoctonia solani

-AG-3, on potato and tobacco, gene flow, S105

- anastomosis group 1, on coffee, characterization, 1054

- anastomosis group 4, fatty acid analysis, 821

-on bean, gene transcript levels, S34

-biocontrol with Microsphaeropsis sp., 782

-Brassica green manure effect in soil, S98

-on East India holly fern, web blight, S61

-hypovirulence, dsRNA induction, S150

-on radish and poinsettia, biocontrol with potting mix, 1116

-on soybean, moisture and temperature effect, S180

Rhizophydium spp., species delimitation, criteria, S116

Rhizopogon vinicolor, phylogenetic species, S116

Rhizosphere, Pseudomonas spp., population density, 44

Rhododendron maximum, ectotrophic symbionts, in Appalachian Mountains, S126

Rhopalosiphum padi, Barley yellow dwarf virus vector, transmission efficiency, 792

Rhynchosporium secalis

- on barley, resistance in Alberta, S191

- phylogenetic analysis of DNA sequences, S32

Riaz, A., S129

Riba, S., S39

Rice

-aflatoxin and fumonisin occurrence, S1

—bacterial panicle blight, bactericides, S33

-blast: disease gradients and epidemics, S42; in

Egypt, characterization, S18; microarray 
analysis, gene identification, S87; multispectral radiometer for assessment, $316 ; \mathrm{Pi}$-ta resistance gene, S44; rapid determination, S44; resistance components, silicon, 63; silicon for cell wall fortification, S49; simulation model, S49

- diseases in tropical Asia, agricultural drivers, S79

-false smut, management in Arkansas, S70

-fungicide control, rates, Arkansas, S23

- seed bacterial population, tropics, 282

- sheath blight, silicon and growth stage effect, S77

—silicon potential, $\mathrm{S} 3$

Rice hoja blanca virus, resistance, plant hopper role, $\mathrm{S} 13$

Rich, P. E., S76

Richards, K., S87

Richardson, B. A., S156

Riddle, L. J., S134

Rideout, S. L., S203

Ried, C. L., 966

Riemann, M., S12

Riera-Lizarazu, O., 702

Riga, E., S142

Riggs, R. D., S130, S139, S142

Riley, M. B., S76

Riley, T., 30

Rioux, D., 1128

Riquelme, M., S122

Rir-Sima-Ah, J., S76, S189

Risk analysis

-CABI database, model, S153

—plant pests, introduction, S153

-review and assessment in USDA, S153

—-standards and obligations, S153

Ristaino, J. B., S59

Ritchie, D. F., S68, S93

Rivas-Davila, M. E., S35

Rivera-Amador, E., S199

Rivera-Varas, V., S94

Rizzo, D. M., S30, S76, S108, S110, S155, S191

RNA silencing, suppression in plants, S162

Robbertse, B., S165

Robbins, R. T., S142, S146

Robens, J., S170

Roberson, R. W., S122

Roberts, D. P., S32

Roberts, D. W., S104

Roberts, I. M., S51

Roberts, P. A., S131, S140, S144

Roberts, P. D., S38

Roberts, R. G., S76

Roberts, S. J., 492

Robertson, A. E., S202

Robertson, D. G., S133

Robertson, N. L., S76, S189

Robinson, A. (Mo.), S36

Robinson, A. F., S142

Robinson, C. H., S121

Robinson, P. W., S77

Robinson, T. L., S66

Robison, D. M., 1109, S51

Roca, M., S71

Rochon, D., S87, S150

Rodgers, J. H., Jr., S157

Rodrigues, C. O., 408

Rodrigues, F., S77

Rodriguez, R. J., S39

Rodriguez-Kabana, R., S133, S137

Roemer, R. L., S184

Rogers, J., S77

Rohlfs, M., S190

Rollins, J. A., S164

Rolshausen, P. E., S77, S89

Romaine, C. P., 905, S18

Romaine, P., 173

Romeiro, A., 408
Romero Montes, G., S33

Rooney, S. N., S189

Rorbaugh, P. A., S188

Rosas, J. C., S200

Rosburg, T., S179

Rose

-debris, Botrytis cinerea and Clonostachys rosea relation, climatic variables, $\mathrm{S} 64$

- gray mold, Ulocladium atrum as antagonist, application factors, S98

- powdery mildew: Armicarb and Pseudomonas aeruginosa combination, sodium bicarbonate, S72; plant extract and foliar fertilizer for control, S101

- Prunus necrotic ringspot virus, variability survey, 84

Rosenberger, D. A., S197

Rosendahl, S., 1231

Rosewich, U. L., S105, S122

Ross, W. J., S23, S70

Rossetto, E. A., S77

Rossman, A. Y., S105, S164

Roth, B., S162

Rothrock, C. S., S65, S201

Rott, M. E., 261

Rotylenchulus reniformis

-on cotton: field response, S137; soil fumigation, S142

-on cowpea and pineapple, reproduction, chemical effect, S132

— crop systems for control, S133

- endoparasitic fungal colonist of, S138

-in pineapple, cover crops for management, S145

-in soil, horizontal and vertical distribution, S137

-on soybean: reproduction, S142; resistance, S94

-thrips interaction, on cotton, S141

- tillage systems and crop effect, S94

Rouppe van der Voort, J. N. A. M., 753

Roux, J., S31, S41, S77, S78

Rouxel, T., 70

Rowe, R., S68

Rowley, K. B., S97

Royals, J. K., II, S203

Royle, D. D., S167

Royse, D. J., 905, S18

Ruben, E., S147, S169

Rubin, E., 579, 1074

Rubinelli, P., S157

Rubio, L., S79, S81, S152

Rubsam, R., S179

Rubus yellow net virus, on berry fruit, Spiraea yellow leaf spot virus similarity, S45

Rudolph, K., S91, S96

Rügner, A., S78

Ruiz-Herrera, J., S165

Rumbolz, J., S74, S78

Rundell, P. A., S72

Rupe, J. C., S65, S78, S201

Rupestris stem pitting associated virus, in grape, detection using recombinant coat protein, S71

Rush, C. M., S84, S96

Rush, M. C., S33

Russell, B. W., S63

Russell, M. D., S167

Russin, J. S., 120. S7, S12, S40, S70, S85, S91, S92, S131

Russula spp.: Lactarius spp. interface, molecular examination, S119; molecular phylogeny in Europe, S119

- R. brevipes, phylogeography and population biology, S102

Rust, DNA sequence, relationships, S127

Ryan, D., S197

Ryder, E. J., 797, S150

Rye, Karnal bunt, phylogeny, molecular syste- matics, 935

Rygiewicz, P. T., S125

Ryley, M., S50

Sabaratnam, S., S78

Sabo, A., S142

Sacadura, N. T., S122

Saddler, G. E., 617

Saenx, G. S., S114, S122

Saftner, R. A., S55

Saint-Jean, S., S78

Sakamoto, J. M., S78

Sakovich, N., S58

Salas, B., S23

Salomon, B.-G., S114

Salomon, R., S80

Samac, D. A., S13, S21, S54, S79

Sams, C. E., S15, S57, S69

Samson, R. A., S170

Samuels, G. J., S105, S109

Sanchez, M. A., S79

Sandbrink, H., S147

Sanders, H. F., Jr., S92

Sands, D. C., S79, S100

Sánez, P., 159

Sanjay, V. C., S6

Sanogo, S., S79

Santos, M. A. A., 408

Santra, D. K., S6

Sarath, G., 204

Satellite panicum mosaic virus, capsid protein, symptoms in nonhosts, S74

Sauerborn, J., S81

Savary, S., S79

Savelle, A. T., 77

Saville, B. J., S122

Sawayanagi, T., 1024

Sawyer, T. L., S45

Sayler, R. J., S79

Sayre, R. T., S157

Scala, A., S197

Schaad, N. W., S74, S79

Schabenberger, O., S130

Schadt, C. W., S122

Schaff, J., S142

Schardl, C. L., 1224, S38, S123

Schaupp, J., S43

Schein, J., S165

Scherm, H., 77, 348, S52, S65, S80

Schiff, N. M., S54

Schilder, A. M. C., S67, S77

Schimelfenig, J., S123

Schisler, D. A., S42, S48, S80, S83, S180

Schizolobium parahybum, ophiostomatoid fungi, S31

Schizophyllum commune

- culture, adaptation, S106

-hymenomycete mating-type genes, 114

Schlang, J., S135

Schlueter, K. O., 797

Schmatz, R., S108

Schmidt, C. A., S37

Schmidt, F. J., S53

Schmidt, L. M., S173

Schmidt, M. E., S37, S85

Schmidt, S. K., S122

Schmit, J. P., S123

Schmitt, D. P., S132, S136, S139, S142, S143, S145

Schmitt, I., S117

Schnabel, G., 102

Schneider, R. W., 120, S51, S80

Schneider, S. M., S80

Schnelle, K., S41

Schnider-Keel, U., 873

Schoch, C. L., S108, S123

Schoelz, J. E., S14, S69, S98

Schoen, C. D., 1085, S88 
Schoeny, A., 694

Scholl, E., S142

Scholler, M., S104

Scholthof, H. B., S27, S63, S68, S162

Scholthof, K.-B. G., 524, S7, S63, S74

Schots, A., S21, S143, S174

Schroeder, K. L., S189

Schroeder, S., S49, S185

Schrunk, J. M., S63

Schultheis, J. R., S12

Schulze, D. G., S88

Schumann, G. L., S90, S198

Schurko, A. M., S123

Schwartz, H. F., S31, S87

Sclerotinia spp.

$-S$. homoeocarpa: isolate detection, PCR primers, S8; physiological diversity in isolates, S72; population dynamics, variation, S40; propiconzale sensitivity, S63

- S. minor: on lettuce compatibility groups, California, S127; mycelial interactions, S19; mycelium compatibility groups, in California, S96

-S. sclerotiorum: ascospores, producing and storing, S175; on canola, tolerance screen in greenhouse, S28; canola genotypes, epidemiology, S115; Colletotrichum trifolii compared to, signaling, S164; on lettuce, Coniothyrium minitans for control, potential with fungicides, 221; nematode-trapping hyphomycetes, in soil, $\mathrm{S} 55$; on potato, variability in Washington, $\mathrm{S} 46$; on soybean, petiole inoculation, S176

Sclerotium

$-S$. cepivorum, garlic powder effect in field, $\mathrm{S} 183$

-S. rolfsii, on hosta, resistance evaluation, S25

Scott, A., S94

Scott, D., S37, S80

Scott, E. S., S48

Scott, R. K., 708

Scott, S. W., S41

Scupham, L., S90

Seah, S. K., S147

Seale, J. W., S13

Sears, B., S77

Sears, J. L., 797, S55, S150

Secor, G., S94

Sedegui, M., S21

Sedun, F. S., S189

Seebold, K. W., 63

Seed decay, green manure amendment effect in soil, S82

Seeds, exchange and global trading, S153

Seem, R. C., 948, S28, S47, S194

Segarra, J., 1001

Séguin, A., S194

Seguin, S. G., S72

Segura, G., S47

Sehly, M. R., S18

Seifers, D. L., S80

Seifert, K. A., S113, S114

Seijo, T. E., S60

Seiridium sp., on Leyland cypress, in Tennessee, $\mathrm{S} 3$

Sellers, P., S171

Semer, C. R., S50

Seong, K. Y., S42, S49, S80

Septobasidium spp., systematics, S112

Septoria musiva, on poplar, recessive resistance, 1081

Serdani, M., S54

Sermons, D. N., S19

Serracin, M., S142, S143

Serratia marcescens

- on cucumber, systemic resistance mediated, iron role, 593

-on cucurbit, vector transmission, S11

—squash bug as vector, parameters, S8
Sétamou, M., S168

Seth, D., S81, S203

Sforza, P. M., S81

Shabana, Y. M., S81

Shabi, E., S103

Shabrial, S. A., 831

Shadwick, J. D., S163

Shah, D. A., 642

Shahjahan, A. K. M., S33

Shamoun, S. F., S181, S183

Shannon, J. G., S139

Shapiro-Ilan, D. I., S143

Sharon, A., 986

Sharon, E., 687

Sharp, L. P., S187

Shaw, B. D., S117, S123

Shaw, M., S74

Shaw, M. E., S76, S184, S186, S189

Shaw, M. W., 240

Shaw, R. S., S81

She, Y.-M., S80

Shearer, B., S50

Shearer, C. A., S105, S110, S121, S123, S163

Sheer, A. M., S81

Shelton, J., S90

Sheng, H., S64

Sheridan, J. P., S143

Sherriff, L., S37

Sherwood, J. E., S5, S50

Sherwood, J. L., S4

Sheta, H. M., S81

Shew, H. D., 1092, S105

Shi, L., S5

Shi, X., S176

Shi, Z. X., S182

Shier, W. T., S1

Shim, W. B., S81

Shiomi, T., 1024

Shirata, A., 181

Shishkoff, N., S196, S197

Sholberg, P. L., S81, S181, S189

Shon, K. J., S46

Short, N., S82

Shrestha, K., S170

Shrestha, R., S82

Shreve, E., S18

Shriver, J. M., 477

Shtienberg, D., 621, S76

Shultz, J., S42, S113

Shuster, J., S38, S55, S165

Siddiqi, M. R., S172

Siddique, K. H. M., S85

Siders, K., S146

Sikora, E. J., S60, S82

Sikora, R. A., 415, S23, S37, S75, S82, S135, S138

Silva, M., S87

Silveira, J. R. P., S68

Silvera, E., S68

Silvers, C. S., S82

Simard, M., 1128

Simpson, C. E., S17, S130

Sims, J. J., S80, S84

Singh, P. K., S190

Singh, R. P., 197

Sipes, B. S., S47, S132, S133, S143, S145

Siripornadulsil, S., S157

Sirococcus spp., on butternut, analysis of isolates, S83

Sivasithamparam, K., S2, S48, S50, S82, S95, S98

Skalchunes, A., S38, S55

Skantar, A. M., S131

Skaria, M., S82, S203

Skinner, P. W., S167

Skirvin, R. M., S16

Skovgaard, K., 1231

Slabaugh, W. R., S82, S190
Slaughter, G. W., S76

Slininger, P. J., S83, S180

Smant, G., S21, S147, S174

Smart, C. D., 882

Smart, J., S94

Smart, W., S98

Smilanick, J. L., S69, S155

Smith, B. J., S2, S4, S16, S204

Smith, D. M., 792

Smith, D. R., S83

Smith, G. J. D., S114, S124

Smith, G. S., S43

Smith, H. J., S143

Smith, K. L., S89

Smith, L. (Minn.), S48

Smith, L. J. (W. Va.), S50

Smith, R., S183, S199

Smith, T. H., S162

Smither-Kopperl, M. L., S135, S167

Smith-White, J. L., S13

Snetselaar, K. M., S165

Snook, M. E., S34

Snover, K. L., S83

Snyder, C. L., S29

Snyder, K. E., S83, S165

Sobek, E. A., S164

Sohn, K. D., S124

Soika, E. L., S90

Soika, M. D., S90

Soil fumigation, dazomet, forest nurseries, S185

Soil microbiology

-micro-community analysis using, fingerprinting of RNA genes, S90

-roots under logs, competition, S118

- saprotrophic fungi in grassland, biodiversity, S121

Soilborne wheat mosaic virus, xylem movement, S151

Sokolski, S., S124

Solofoharivelo, M. C., S83

Soltani, N., S1

Somasekhar, N., S143

Son, J.-H., S124

Sorghum

-anthracnose and leaf blight, crop mixtures, 720

- charcoal rot, marker differentiation, 120

- ergot, AFLP isolate analysis, S89

- ergot, weather patterns in Texas, S96

Sorghum bicolor, anthracnose, infection ultrastructure, 149

Sosinski, B., S97

Soto, M. J., S83

Souza, N. L., S71

Soybean

- aerial blight, temperature effect, S51

-Alfalfa mosaic virus, pathogenesis and chimeric rabies peptide, 941

-Bean pod mottle virus, resistance, transformation, 831

-brown stem rot: soil $\mathrm{pH}, \mathrm{S} 178$; susceptibility increased by Heterodera glycines, $\mathrm{S} 87$

- charcoal rot: marker differentiation, 120; nodulation, nitrogen fixation, sudden death syndrome, S70; resistance, $\mathrm{S} 85$

- cyst nematode: BAC library for cellulase gene organization, S97; bacterial association, S136; brown stem rot relation, resistance, $\mathrm{S} 178$; crop rotation and resistance, S145; field distribution, S133; Fusarium solani resistance compared, S147; gene discovery, S174; juvenile lipid content, S145; life cycle gene, S137; mycoflora in Minnesota, S15; parasitism genes in esophageal glands, S134; parasitism genetics, S147; race tests and container effect, $\mathrm{S} 142$; races in Illinois, S85; resistance, S133; resistance breakdown and gene evolution, S169; resistance evaluation methods, S146; resistance identified, S176; spread in Ontario, 
S87; stress measured by GIS and remote sensing, S167; sudden death syndrome, yield reaction, S43; survey in North Dakota, S65; tillage and spatial pattern relation, 534

— disease resistance gene map, S42, S113

-dry rot, in Minnesota, S177

-fungal diseases in North America, range and diversity, 769

-Fusarium solani, gene analysis, S42

-lactofen application, trials and results, S175

-nematodes, cropping sequence for control, S137

—pathogens, soil properties, in Illinois, S131

- Phytophthora root rot, chitinase and glucanase expression patterns, S56

_ pod and seed mycoflora, in Mississippi, S203

-pod and stem blight, azoxystrobin for, S80

-Pythium spp., cultivar resistance, S201

-Pythium, seed exudate relation to resistance, S65

-Rhizoctonia root and crown rot, resistance evaluation, S175

-Rhizoctonia root rot, yield loss, S10

-root rot, chisel and moldboard tillage effect, S27

-Sclerotinia stem rot: growth stage effect, S179; plant density, population, and row spacing effects, S178; prevalence prediction mid-term, S62; SoilGuard application, mycorrhizae, S44

- seed infection, Phytophthora and Fusarium, detection, S55

- sprout rot pathogens, pesticides for, S4

-stem canker: resistance screening, S32; in South Dakota, S15

- sudden death syndrome: factors, S91; field inoculation method, S97; field response inheritance, S37; furrow-irrigated field, S78; soil physical environment, S92

- viruses and green stem, Wisconsin, S176

Soybean dwarf virus, coat protein genes, diversity in Japan, S2

Spaine, P., S83

Sparks, D., S98

Sparrow, A. D., S157

Spatafora, J. W., S112, S116, S125

Species

- fungi, lineages and phenotypes, S151

-range size prediction, climate analysis, S153

Species concepts

-asexual fungus classification, S151

- gene flow analysis, boundaries, S152

-regulatory issues, S151

Species diversity, fungi, statistical comparison of communities, $\mathrm{S} 108$

Sphaceloma manihoticola, on cassava, virulence in Brazil and Colombia, S101

Sphaeropsis sapinea

-morphotypes, gene genealogies, S22

-on Austrian pine, PCR protocol, S28

-on pine, dsRNA elements, S22

—on Pinus nigra, ferulic acid effect, S9

Spiegel, F. W., S163

Spiegel, Y., 687

Spielmaker, D., S171

Spinach, white rust, fungicides, S86

Spiroplasma, corn stunt, insect and plant interaction, S31

Spiroplasma citri, adhesion-related protein SARP1, S8

Spore sampler, Burkard cyclonic, efficiency, S175

Sporobolus cryptandrus, viability and germinability in storage, $\mathrm{S} 112$

Spotts, R. A., S83, S190

Sreckler, R. M., S84

Sschleuter, K. O., S150

Stack, R. W., S23, S84, S178, S179

Stagonospora nodorum -on wheat, molecular markers, S37

-on winter wheat, epidemiology and spatial pattern, 642

Standing, K. G., S80

Stange, R. R., S39, S84

Stanghellini, M. E., S48, S62, S74, S84, S188

Staniulis, J., S91

Stanosz, G. R., S20, S83, S108

St-Arnaud, M., S28, S34, S44

Starner, V. R., S84

Starr, J. L., S17, S130

Starratt, A. N., S78

Stavely, J. R., S70

Stead, D. E., 617

Steadman, J. R., S2, S175, S199, S200

Steddom, K., S84

Steenackers, M., 1069

Steenkamp, E. T., S124

Steffenson, B. J., 469

Stehmann, C., 633

Stein, J. M., S50

Steiner, U., S67, S85

Steinernema spp., new species from China, S132

- S. carpocapsae, isolate diversity, S143

-S. feltiae: juveniles, temperature effect, S135; on tomato, Meloidogyne incognita suppressed by, timing, $\mathrm{S} 140$

- S. ribobrave, Diaprepes abbreviatus affected by, soil factors, S133

Stemphylium spp.

- homothallism, S111

-molecular phylogeny, gene sequences, S104

Stenger, D. C., S11, S29, S85

Stenlund, D. L., S185

Stenocarpella maydis, on maize, molecular detection, S191

Stenotrophomonas maltophilia

—chitinase from, biocontrol agent, 204

- chitinolytic activity and genetic analysis, biocontrol agent, S8

Stensvand, A., 1172

Stephenson, J., S35

Stephenson, S. L., S124

Stepien, V., S85

Stetina, S. R., S7, S85

Stevens Johnk, J., 821

Stevens, J., S85

Stevenson, K. L., S63, S85, S89, S148, S203

Stewart, E. L, S34, S105

Stienman, J., S25. S93

Stienstra, W. C., S130

Stiles, C. M., S86

Stinner, R. E., S89

Stipanovic, R. D., S40, S95

Stirling, B., 981

St-Michel, É., S8

Stock, S. P., S132, S135

Stocks, I., S130

Stockwell, V. O., S45, S86, S87, S190

Stone, A. L., S20

Stone, J. K., 1214, S186, S191

Stoner, M. F., S190

Storer, A. J., S78

Storme, V., 1069

Strawberry (see also Fragaria spp.)

-anthracnose: biocontrol agents, S88; early ontogeny, S4; germination and sporulation factors, S53; persistence and interaction on hosts, 986; phyllosphere ecology, 659

-black root rot, fungus-nematode interaction, S195

-Botrytis fruit rot: fenhexamid for control, S62; fungicides, rates and schedules, S54

- Colletotrichum crown rot, non-strawberry hosts, S57

- gray mold: biocontrol with yeast and bacteria, 621; control with Ulocladium strains, 1030

-IR-4 methyl bromide program, review, S66 -leaf blight, estimated severity, S66

-Phomopsis leaf blight, sequential sampling, 336

-root disease management, S58

-Verticillium wilt, cultivar and density effect, S36

Streptomycetes

- antibiotic activity diversity, prairie plants, S95

— genetic diversity in prairie soil, S54

- pathogen inhibitory potential, green manure effect, S49

-in soil, antibiotic inhibition and resistance, S21

Stromberg, E. L., S81

Stromberg, K. D., S49

Strunnikova, O., S126

Stubbs, C. S., S3

Sturbaum, A. K., 882

Sturhan, D., S143

Stutz, J. C., S107

Styer, W., S31

Stylosanthes guianensis, Rhizoctonia foliar

blight, transformation for resistance, S47

Su, G., 120, S190

Suassuna, N. D., S86

Subbarao, K. V., 134, S8, S45, S96, S114, S127

Sudarshana, M. R., S44

Sudduth, K. A., S133

Sudhaus, W., S172

Suga, H., 1054

Sugar beet

-Aphanomyces soil index, hymexazol treatment, S95

- Beet necrotic yellow vein virus and Beet soilborne mosaic virus interaction, effect on beet, $\mathrm{S} 150$

- Cercospora leaf spot: fungal antagonists, S53; fungicides, S48

- cyst nematode, green manure crop effect, S134

-Fusarium yellows, variability in isolates, S36

—nematode, integrated management, S143

—nematodes on, oil seed meal effect, S135

-nonpathogenic phyllosphere-inhabiting bacterium, S5

-Rhizoctonia root rot: disease severity rating, S45; Quadris application, S36

-Rhizoctonia root and crown rot, azoxystrobin for, $\mathrm{S} 175$

—Rhizoctonia solani, defense response, S65

—rhizomania disease, crop rotation effect, S184

Sugar, D., S155

Sugarcane yellow leaf virus, yield loss and juice quality changes, S33

Sugiyama, T., 1166

Sugui, J. A., S149

Suh, S.-O., 120, S124

Sui, D. D., S86, S203

Sullivan, K. F., S127

Sullivan, M. J., S86

Sullivan, R., S103, S117

Summerell, B. A., S13

Sun, X., 30

Sunazaki, K., S86

Sundaram, S., S86

Sundararaj, P., S134, S135

Sunflower, exposed to contaminated soils, plant effect, S157

Sung, G.-H., S125

Suppressive soils, aluminum-peat for Phytophthora parasitica suppression, 1092

Survival, animal-waste application sites, pathogens in sites, S73

Suslow, T. V., S38, S154

Sutton, E. A., S23, S70

Sutton, J. C., S68

Sutton, L. A., S2

Sutton, T. B., S26

Sutula, C. L., S97

Suzuki, N., S150 
Swan, B., S87

Sweet cherry (see Cherry)

Sweetingham, M. W., S194

Sweet potato

-Rhizopus soft rot, injury and storage duration effect, S39

-yield and root quality, S12

Sweet potato feathery mottle virus, on sweet potato, yield and root quality, S12

Sweet potato leaf curl virus

- genetic diversity, S56

— properties, S56

Sweigard, J. A., S162

Swennen, R., S38

Swift, C. E., S87

Swings, J., 282

Sycamore, dieback, Alabama and Mississippi, S54

Sylvester-Bradley, R., 708

Symbiosis, nematodes and bacteria, S145

Sysak, R. W., S77

Systematics, geological time, S164

Szalanski, A. L., S139, S143, S173

Sztejnberg, A., 1062

Tabor, G. M., S87, S180

Taga, M., 354

Tagetes erecta, Alternaria leaf spot, fungicide control, S35

Takamura, K., S122

Takano, Y., S87

Takeda, T., 1166

Takikawa, Y., 617

Takken, F. L. W., S161

Tan, J., S125

Tan, L., S144, S173

Tande, C., S15

Tangonan, N. G., 1054

Tanguay, P., S194

Tanne, E., 741

Tanzer, M., S38, S55, S165

Tapesia yallundae, T. acuformis comparison, mating type distribution, S24

Tavantzis, S. M., S150

Taxonomy, molecular, conserved DNA sequence in detection, $\mathrm{S} 152$

Taylor, C. R., S133

Taylor, J. D., 492

Taylor, J. W., S114, S121, S151, S164

Taylor, K. C., S75

Taylor, S. E., S32, S94

Teaching

- adult learners and technology, S169

— digital databases, resources, S146

- disease triangle, model for introductory courses, S39

- Internet guide, S170

-online course, $\mathrm{S} 10$

-problem-based learning, S76

-Web for plant disease, S169

-Web page design, S169

Tebeest, D. O., S93

Tefft, P. M., S145

Teixidó, N., S155

Temple, T. N., S87

Tennant, T., S117

Tenuta, A. U., S87, S145

Teplitski, M., S160

Terauchi, H., S2

Terborgh, J., S112

Terry, N., S157

Tetropium spp., ophiostomatoid fungi association, S113

Tewari, J. P., S191

Thacker, J., S125

Thaker, M., 966

Thakur, R. P., S169

Thanatephorus cucumeris, on bean, genetics and sequence analysis, S199

Theilmann, J., S87

Thies, J. A., S144

Thies, W., S155

Thinopyrum intermedium, Barley yellow dwarf virus in, resistance, 55

Thomas, C. (Ga.), S37, S80

Thomas, C. E. (S.C.), S45

Thomas, C. S. (Calif.), S167

Thomas, F., S157

Thomas, P. E., S87

Thomas, S. H., S144

Thomas, W. K., S131, S173

Thomashow, L. S., 35, 44, S186

Thompson, C., S40

Thompson, D. C., S66, S84, S88

Thompson, I. A., S41, S88

Thompson, J. R., S88

Thompson, T. R., S180

Thomson, S. V., S67, S88, S172, S191

Thorpe, D. J., S88

Thrips setosus, Tomato spotted wilt virus replication in, midgut cells, 1149

Tian, T., S55, S152, S88

Tilletia spp.: in combine debris, regional survey, S71; Karnal bunt, phylogeny, 935; taxonomic characters, S182

-T. controversa: global wheat trade effect, S153; species boundaries, definition, S151

Tilletiales, generic limits, evaluation, S105

Timmer, L. W., S70, S71, S88, S99, S188, S190

Timper, P., S144

Tiourabaev, K., S100

Tobacco (see also Nicotiana spp.)

-Agrobacterium vitis on, hypersensitivity, 966

— cyst nematode, density and damage, S52

-Pythium root rot: chitosan for control, S202; fungicide for, S27; management in greenhouse, S35

-root-knot, broadcast fumigation, S29

- systemic resistance marker PR1a, Oxycom stimulation, $\mathrm{S} 9$

Tobacco mild green mosaic virus, on Solanum viarum, hypersensitivity, S71

Tobacco mosaic virus

_-gene silencing suppression, S162

-necrotic lesion formation, Arabidopsis gene, S42

- seed transmission, S35

Tobacco rattle virus, trichodorid nematodes, molecular diagnostic, S10

Tobias, D. J., S178

Tobiasz, M., S194

Todd, J. W., S57, S60

Tomato (see also Lycopersicon peruvianum)

-bacterial speck, acibenzolar-S-methyl for control, S2

-bacterial spot, ammonium lignosulfonate and potassium phosphate application, $\mathrm{S} 1$

-Fusarium oxysporum on roots of, colonizations and biocontrol, 449

-hypersensitivity, host cell and Ralstonia solanacearum, nitric oxide radical, S66

-inoculum in wounds, S6

-late blight, oospores on fruits and seeds, 1074

-nematodes, oxamyl, nematodes, and Serratia marcescens effect, S129

-organic, management practices, S50

-Phytophthora infestans, virulence complex in Washington, 606

-postharvest pathology, pathogenesis-related proteins, S194

-Rhizoctonia damping-off, Beauveria bassiana effect, S81

-Rhizoctonia solani and damping-off, S203

-root-knot nematode: molecular marker, 377; resistance gene, $\mathrm{S} 136$

—root-knot and aphids, resistance genes, S147 —root-knot and Fusarium wilt, rhizobacteria antagonist, S37

- Southern blight, composts and amendments for control, S57

- streptomycetes from, damping-off and root rot control, S78

- xanthomonads in seeds, detection by PCR assay, S19

Tomato bushy stunt virus

-defective interfering RNAs, host specificity, S68

— gene silencing suppression, S162

-host factors, S27

-Lettuce necrotic stunt virus relation, 797

-relation to virus on lettuce and tomato, S150

Tomato chlorosis crinivirus, on tomato, transmission by whiteflies, S96

Tomato spotted wilt virus

- peanut response to, S57

-replication in Thrips setosus, in midgut, 1149

-replication in thrips vector, S4

- on weeds, thrips overwintering on, 891

Tomato yellow leaf curl virus

-resistance and transmission by whitefly, 1209

- transmission pathway in vector, 188

Tomback, D. F., S155

Tondje, P. R., S10

Tooley, P. W., S58, S89

Topp, E., S145

Torigoe, Y., 316

Torzilli, A. P., S118

Toth, S. J., S89

Toussaint, V., S89

Towers, G. H. N., S29

Towers, G. W., S197

Traphagen, L. M., S30

Traquair, J. A., S78

Travis, J. W., S34

Tredway, L. P., S89, S148, S203

Tremblay, D., S89

Trently, D. J., S61

Triana, M., S13

Trichoderma spp.: biocontrol, Hypocrea teleomorphs, S105; sect. Trichoderma, DNA sequences, S109

-T. atroviride: biocontrol agent, protein induction, S31; mycoparasitism, chitinase activity, S187

- T. hamatum, detection by PCR, S19

-T. harzianum: biocontrol agent for root-knot nematode, 687; biocontrol efficacy, nematode effect, 301; Botrytis cinerea inhibited by, nutrient-activated conidia, 1172; endochitinase role in parasitism, factors, S168; endochitinases, sequence analysis, S184

-T. virens: $T$. atroviride comparison, antibiotic properties of fusant, S95; T. longibrachiatum comparison, protoplast fusants, S40

Trichodorus spp., Paratrichodorus comparison, virus transmission, $\mathrm{S} 46$

Trichomycetes

—on black flies, in South Carolina, S102

-relationships using ribosomal DNA, S126

- species richness, in gut fungi, $\mathrm{S} 104$

Trigiano, R. N., S81

Trinidad-Correa, R., 1156

Triticum aestivum, on wheat, heritability and transgressive segregation, 680

Triwitakorn, K., S42, S147, S169

Tronsmo, A., 1172

Trouillas, F. P., S77, S89

Trout, T. J., S12, S80

Troxclair, N., S54

Troxell, T. C., S170

Trudell, S. A., S125

Trypanosome, plant parasites, phosphatase activity, 408

Tsuchiya, D., 354 
Tsuchiya, K., 399

Tsuda, S., 1149

Tsuga canadensis, health monitoring, satellite use, S167

Tsuge, T., S70

Tsui, C. K. M., S125

Tsukamoto, T., 181

Tubajika, K. M., S89

Tudor, S., S38

Tunlid, A., S149, S173

Turechek, W. W., 336, S37, S157

Turfgrass

-brown patch, fungicides and management practice, $\mathrm{S} 198$

- cuticle, dissolution effect, S127

- fungicides, broad spectrum, S202

-Tylenchorhynchus on, Pasteuria infection, S198

Turgeon, B. G., S56, S122, S123, S159

Turgeon, G., S5, S165

Turina, M., S90, S150

Turini, T. A., S74, S84, S90

Turkensteen, L. J., 882

Turkington, T. K., S191

Turnbull, G. D., S41

Turner, D. W., S98

Turner, P. C., S171

Turnip crinkle virus

-on Arabidopsis, defense signaling, S159

- defense signaling, resistance, S45

Tuttle, N. T., S59, S180

Tweddell, R. J., S196, S198

Tworkoski, T. J., 1098, S43

Tylenchidae, fungal-feeding nematode, in rice straw, S140

Tylenchorhynuchus claytoni, on creeping bentgrass, $\mathrm{S} 93$

Tylenchulus semipenetrans, on citrus, virulence mitigation by Phytophthora nicotianae, S137

Tylka, G. L., 534, S87, S130, S139, S167, S180

Typas, M. A., S126

Typhula spp., detection and characterization, S45

- T. ishikariensis, genetics among three groups, S121

Tytgat, T., S144

Tzeng, D. D. S., S66

Uchida, J. Y., S90

Uchida, R. S., S90

Uddin, W., S90, S92, S147, S148, S198

Ueng, P. P., 642, S20

Ugaki, M., 1024

Ullman, D. E., S26, S81

Ulloa, M., S110

Ullrich, H., 511

Ulocladium atrum

- antagonism to Botrytis cinerea, water potential effect, 485

-biocontrol with Botrytis cinerea, on strawberry, 1030

-on strawberry, antagonism to Botrytis cinerea, S8

Umana, L., S163

Uncinula necator

-on grape: early colonization of buds, S74; early development in field, S78; epidemiology, 948; host barriers, S28; monopotassium phosphate effect, S193; ontogenic resistance, S194

-relative humidity effect on sporulation and germination, S75

Unlu, A., S6, S90

Uphoff, M., S97

Upton, C., S43

Uromyces appendiculatus, on bean

-pathogenic variability monitoring, S200; photosynthetic competence, 212; virulence pattern in Nebraska, S2; yield loss, 1045

-Uropyxis petalostemonis, on white clover, rain effect, S30

Usall, J., S69, S155

Ustilago spp., sex, signaling, and morphogenesis, S165

-U. hordei, pheromone-derived peptides from, farnesyltransferase, S50

-U. maydis: dimorphic transition, signal transduction, S165; dimorphism and pathogenesis, gene expression, S30; dimorphism, genes, S83; genetic variation, inbreeding, S6; interaction and genetics, S165; morphological mutants, S165; morphology and pathogenicity, calcineurin catalytic subunit, S25; protein phosphatase role, dimorphism and pathogenicity, $\mathrm{S} 25$; saprobic to parasitic growth, transition, S165; teliospores, germination and gene expression, $\mathrm{S} 122$

-U. zeae, genomics-based approaches, control, $\mathrm{S} 158$

Vaiciunas, S. S., S148

Vaillancourt, L. J., 558, 616, S28

Valasco, V., S87

Vale, F., S77

Valent, B., S44

Valinsky, L., S90

Valiunas, D., S91

Valverde, R. A., S56

van 't Klooster, J. W., S161

Van, T. K., S75

Van Alfen, N. K., 17, S47, S60, D90, S150

Vanasse, A., S44

van Berkum, P., S5, S104

van Bruggen, A. H. C., 134

VanCauwenberge, J. E., S180

Vance, V. B., S162

Vandamme, P. A. R., S173

Vandemark, G. J., S53, S91, S186, S191

van den Bosch, F., 1001

van den Bosch, T. B. M., 882

van den Heuvel, J. F. J. M., 1085

van der Hoef, A., S78

van der Hoorn, R. A. L., S161

van der Vossen, E., S147

VanEtten, H. D., 92, 820, 1156

Vanfleteren, J., S133

Vargas, J. I., S91

van Ginkel, M., 55

van Heerden, S. W., 628

Van Iersel, M., S12

van Koert, P., 753

Van Montagu, M., 1069

Vazquez, M. R., S91

Vector, virus-based, tat protein in plants, S46

Vedova, G. D., S90

Velasquez, L., S20, S91

Veneklaas, E. J., S85

Venette, J. R., S177

Venette, R. C., S153

Venkatesh, B., S91

Venter, M., S125

Venturia spp.

- V. inaequalis: on apple, fungicide resistance, predisposition, 776; on apple, infection process and melanin role, S85; on apple, lesioncausing efficiency, S17; on apple, myclobutanil resistant strains, molecular basis, 102; on apple, relation with $V$. pirina, 633; ascospore depletion, leaf wetness and duration effect, S72; population structure, in Israel, S103

-V. nashicola, PCR identification, spacer region in DNA, 900

-V. pirina: on apple, asci and conidia, cover photo, July; on pear, sex on apple, 633

Vercauteren, I., S144

Verchot, J., S151

Veremis, J. C., S144
Vergnet, C., S77

Verma, D. P., S157

Vernia, C. S., S111

Vernon, P. R., S18

Verticillium spp., molecular variation, S126

-V. dahliae: on eggplant, root endophytes, S187; ELISA for detection, S97; medium from soil recovery, 114; on pistachio, salinity effect, S5; in soil, recovery medium, S45; vegetative compatibility and polyphenol oxidase activity, S8

-V. fungicola: on mushroom, molecular phylogenetic analyses, 905, S18; spent mushroom substrate effect, $\mathrm{S} 195$

- V. longisporium, on horseradish roots, in Illinois, S16

Vest, J. D., S85, S91

Vestey, E., S184

Vicente, J. G., 492

Vick, C. M., S85, S92

Vierling, R. A., S133

Vierstraete, A., S133

Viji, G., S90, S92, S148, S198

Vilgalys, R., S105, S112, S114

Villalobos, R., S32

Villanueva, E., S96

Villarroel, D. A., S203

Viñas, I., S69, S155

Vincelli, P., S92

Viruses

- conserved nucleotide sequence, differentiation, S152

-epidemiology, cross-protection model, 924

-fungi, system introduction, S149

- transmission, plasmodiophorid vectors, S151

-RNA, capped and uncapped, translation inhibition, $\mathrm{S} 92$

-RNA silencing, suppression, S161

Visser, A. J. W. G., S143

Vitorello, C. B. M., S158

Vivanco, J. M., S69, S92

Viveros, M., S11

Voland, R. P., S61

Volk, T. J., S111, S126

Völksch, B., 511

von Bodman, S., S160

von Broembsen, S. L., S92

Voth, P., S126

Waalwijk, C., 1037, 1181

Wahl, M. S., S110

Wahsh, S., S18

Wake, K., S165

Walcott, R. R., S69, S92

Walgenbach, J. F., 891

Walker, J. F., S126

Walker, N. W., S93

Walker, S. L., S37, S59

Walkinshaw, C. H., S93, S204

Wall, G. C., S200

Walsh, K., S145

Walters, S. A., S144

Wang, H. L., S93, S191

Wang, J., S123

Wang, K., 546, S145

Wang, N., S106

Wang, X., S5, S134

Wang, Y., 565

Wangsomboonsee, T., S93

Ward, T., S151

Ware, G. O., 348

Ware, S. B., S93

Warnkes, S., S20

Warrior, P., S30

Warrior, U., S30

Wasilwa, L. A., S93, S180

Watermelon (see also Melon)

-bacterial fruit blotch, peroxyacetic acid as seed 
treatment, S40

-fruit blotch, PCR diagnosis, S79

- powdery mildew, races 1 and 2 compared to muskmelon, S197

- vine decline, unknown etiology in Indiana, S26

Watermelon silver mottle virus, genome sequence, degenerate primers, 361

Waterston, R., S159

Watkins, C. B., S166

Watkins, J. E., S123

Watson, M., S72

Waugh, M. M., S48, S74, S84

Wayadande, A., S8, S11

Weather, site-specific estimation, accuracy in Costa Rica, S32

Weaver, C. F., S133

Weber, A., S93

Weber, D. J., S126

Weber, J. T., S154

Webster, J. M., S132, S141, S145

Webster, R. M., S167

Wedge, D. E., S94, S204

Weeds, Tomato spotted wilt virus, relation to thrips, 891

Weeks, J. R., S60

Wegulo, S. N., 659, S7, S25, S53, S88, S94

Wehland, M., S160, S196

Wei, J. Z., S135, S145

Wei, Z.-M., S74

Weibel, E. N., S198

Weiland, J., S94

Weingart, H., 511

Welacky, T. W., S87, S130, S132, S145

Welch, M., S160

Weller, D. M., 35, 44, S52, S61, S186, S187, S189

Welliver, R., S20, S32

Wells, J. M., S145

Wells, K. D., S124

Wells, L., S94

Weng, Z., S83, S94

Wergin, W. P., S140

Weseloh, R. M., S110

Westerdahl, B. B., S134, S141, S145

Westerink, N., S161

Westfall, P. J., S126

Westmoreland, S., S126

Westphal, A., S94

Wetteroff, J. J., Jr., S104

Wharton, P. S., 149

Wheat

- Anguina tritici, cultivar reaction, S129

-apple replant soil affected by, pseudomonad population, S33

-Barley yellow dwarf virus, resistance, 55

-Cephalosporium stripe: toxin and disease susceptibility, 702; transformed isolate, 232

-Fusarium head blight: biocontrol, Tween-80 effect, S48; control in Germany, S67; epidemic prediction and risk, S22; fungicides, S177; inoculum detection and disease progress, environment, S68; monitoring progress, S177; recombinant population, $\mathrm{S} 179$; resistance sources, S84

-Fusarium spp., scabby kernel detection, S23

-High Plains Disease, molecular characterization, S63

-leaf spot, tillage effect in Manitoba, S32

- powdery mildew, prevention with oils, S197

- puroindoline proteins, anti-fungal activity, S5

-rhizosphere, bacterial community evaluation, S61

-rhizosphere pseudomonads, antibiotic populations, S52

-root and foot rot: control methods, S109; physical, chemical, and biological control methods, S26 —root health problems, Saudi Arabia, S7

-Septoria tritici blotch: pseudothecia and genetic recombination, 240; resistance inheritance, S60

-Stagonospora nodorum blotch, spatial pattern and disease incidence, 642

- stripe rust: resistance genes, RGAP markers, S182; RGAP markers, S97

-stripe rust and yellow rust, heritability and transgressive segregation, 680

—-strobilurins, yield effect, S67

—take-all: bacterial associations, S187; yield formation and loss, 694

- tan spot: chlorosis and resistance genetics, S190; race resistance, RFLP map, 572; recombinant inbred population, S30

Wheat streak mosaic virus

- cultivar resistance, S178

- genetic isolation, S85

-P3 cistron, replication and movement, mutations, S29

-on winter wheat, inoculum dilution effect, S175

-yield and growth reduction, S52

Wheat yellow head virus, in Kansas, S80

Wheatgrass, bacterial leaf streak, S187

Wheeler, I., S34

Wheeler, M. H., S95

Wheeler, T. A., S146

Whelan, R. E., S37

Wherrett, A. D., S95

Whipps, J. M., 221

Whitcomb, S. A., S107

White, D. G., S17, S50, S59, S62, S115

White, J. F., S30, S103, S117, S194, S195

White, J. H., S135

White, M. M., S126

Whitfield, A. E., S26

Whiting, C., S185

Whiting, E. C., S191

Wick, A. A., S95

Wick, R. L., S198

Wickliffe, E., S87

Widstrom, N. W., S34, S98

Wiecko, A. T., S200

Wiersma, J. V., S23

Wiggins, E., S49

Wilcox, W. F., 776, 948, S47, S100, S193

Wild, C. P., S171

Wilke, A. L., S95

Williams, H. J., S95

Williams, S. A., S174

Williams, W. P., S96

Williamson, L., S95

Williamson, V. M., S138, S147

Williams-Woodward, J. L., S69, S95

Willie, K., S15

Willis, D. K., S49

Wilson, A. D., S95

Wilson, C. D., S189

Wilson, C. L., S21, S155, S166, S193

Wilson, C. R., S17, S71

Wilson, D. M., S11, S34

Wilson, J. P., 255, S169, S204

Wilson, L. L., S66

Wilson, R. G., S36

Windels, C. E., S25, S95, S175

Windham, A. S., S3, S81

Windham, G. L., S96

Windham, M. T., S3, S81

Windom, G. E., S182

Winfield, L. E., S157

Wingfield, B. D., 628, S22, S31, S41, S77, S106, S124, S125, S127

Wingfield, M. J., 628, S22, S23, S31, S41, S77, S78, S101, S106, S113, S124, S125

Winter, D., S118

Wintermantel, W. M., S96, S150
Winton, L. A., S186

Winton, L. M., S189, S191

Wirtz, N., S117

Wisler, G. C., 797, S150

Wisniewski, M., S155

Witt, F., S96

Wolak, F. J., S139

Wolf-Hall, C. E., S84

Woloshuk, C. P., 616, S61

Wolpert, T. J., 702

Wolyn, D., S184

Woo, K. S., S156

Wood decay

-fungi association, thinning treatments, Idaho, S118

- poroid fungi, biogeography in North Carolina, S111

-in red oak, detection, S44

Wood, D. L., S78

Wood, G., S170

Wood, T. F., IV, S61

Woodfield, D. R., S139

Woods, S. M., S32

Workneh, F., S96

Worrall, J. J., S127

Wright, A. J., S149

Wright, P. T., S127, S146

Wrobel, R. L., S147

Wu, B. (Pa.), S148

Wu, B. M. (Calif.), 134, S96, S127

Wu, H.-J., S45, S159

Wu, J., S28, S165

Wu, Y., S13

Wuest, P. J., S3, S195

Wurms, K., S96

Wydra, K., S96

Wyss, U., S46

Xanthomonas spp.: on citrus, host-specific pathogenicity genes, S152; on rice seed, saprophytic, 282

-X. axonopodis: on citrus, genotypes in Florida, S19; on pepper, strain competition, mutation, S93; on Rosa damascane, antibacterial effect of oil, S6

-X. campestris: antagonism of strains, bacteriocin-like genes, S38; on cassava, cultivar resistance, S96; detection of AND plasmids, S199; genetic diversity, pathogen/host coevolution, S64; races and pathovars, origin, 492; replication slippage frequency, in $a v r B s 2$ gene, S40

-X. pruni. on peach, management strategy in New York, S37

Xanthosoma spp., diseases of, control strategies, S199

Xi, K., S191

Xia, J. Q., S97

Xia, Z., S191

Xiao, C. L., S36, S57

Xie, W., S1

Xie, Z., S161

Xiong, Z., S83, S94

Xiphinema spp.

-X. diversicaudatum, inter-population heterogeneity, S65

-X. index, monoclonal antibodies, screening, $\mathrm{S} 15$

Xu, J. (China), 377

Xu, J. R. (Ind.), S117, S120, S127

$\mathrm{Xu}, \mathrm{R} ., \mathrm{S} 97$

Xue, A., S99

Xue, C. Y., S127

Xylariales, molecular systematics, sequence data, S124

Xylella fastidiosa

_biofilm-forming bacteria, S58

-on citrus and coffee, genetic diversity in Brazil, 
599

- on citrus and weeds, epidemiology in Brazil, S77

- terpene effect on growth, S14

- transposon mutagenesis, S34

-tRNA-tRNA genes, S16

Xylobolus spp., phylogenetic relationships, S117

Yaegashi, S., S42, S113

Yaganza, E. S., S198

Yaghoobi, J., S147

Yahr, R., S127

Yakoby, N., 143

Yakorn, K. T., S113

Yamak, F., S192

Yamashita, M., S86

Yan, G. P., S97

Yan, Y., S97

Yandoc, C. B., S97

Yang, D.-Q., 369

Yang, G. H., 680

Yang, H. A., S194

Yang, K. Y., S9, S98

Yang, X. B., 680, 769, S62, S97

Yang, Y., S44, S73, S98

Yang, Z. N., S97

Yarden, O., 1062

Yates, D., S50

Yates, I., S98

Ye, W., S146

Yegen, O., S6

Yeh, S.-D., 361

Yeh, S.-H., 856

Yencho, G. C., S12

Yersinia enterocolitica, lactone signal, genetically modified plants, S160

Yin, B., S90, S98

Yoder, O. C., S5, S56, S123, S159, S165

Yohalem, D. S., 527, S98, S120
Yokogi, T., S59

Yoon, K. S., S124

Yoshida, S., 181

Yoshioka, H., S86

Yoshioka, K., S45, S159

Young, B. G., S40, S131

Young, J. (New Zealand), S41

Young, J. M., 617

Young, L. D., S146

Young, N. D., S137

Young, S., S63

Yourman, L. F., 307, S61

Ypema, H. L., S5

Yu, H., S68

Yu, W., S98

Yuan, C., S98

Yuen, G. Y., 204, S48

Yuen, J. M. F., S66

Yulianti, T., S98

Yun, J. I., S49

Yusibov, V., 941

Zablotowicz, R. M., S1

Zadig, D., S153

Zainab, A.-S., S35

Zak, J. C., S164

Zambolim, L., 1045, S77

Zapata, M., S199, S200

Zasada, I. A., S146

Zasoski, R. J., 324

Zeller, K. A., S54, S91, S99

Zeller, W., S6

Zellers, J., S133

Zettler, F. W., S71

Zhan, J., 1011

Zhang, B., S14

Zhang, H. B. (Tex.), S42, S113

Zhang, H. S. (N.Y.), 966

Zhang, H. (Wash.), S70
Zhang, J. (Belgium), 1069

Zhang, J. X. (Canada), S99

Zhang, J. X. (Fla.), S99

Zhang, N., S127

Zhang, S., S98

Zhang, W., S38, S55, S165

Zhang, X. (S. Dak.), S44

Zhang, X.-S. (UK), 924

Zhang, Y. (N.C.), S159

Zhang, Y. H. (China), S55

Zhang, Z. (Nebr.), 204

Zhang, Z. J. (China), 680

Zhao, Y. (Md.), S99

Zhao, Y. F. (Okla.), S204

Zheng, D., 966

Zheng, J., S10

Zheng, X. B., S99

Zhong, S., 469

Zhong, Z., S128

Zhou, H., S106

Zhou, R., 143

Zhou, X. G., S100

Zhu, Q., S44

Zhu, T., S159

Zhu, Y., S151, S157

Zidack, N. K., S5, S100

Ziems, A. D., S100

Zimmerman, M. T., S41

Zismann, V. L., 648

Zitka, M., S197

Zitko, S., S71

Zitomer, N., S51

Zitter, S. M., S100

Zobrist, K., S147

Zoffoli, J. P., S69

Zoller, S., S128

Zou, G., S159

Zunke, U., S146

Zveibil, A., 586 